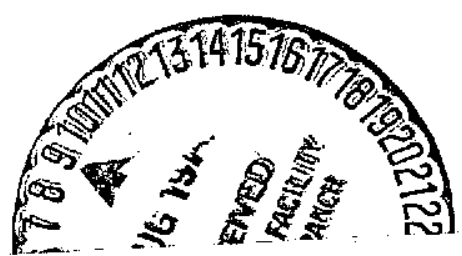

(NASA-TM-X-71587) AERODYNAMIC AND

\title{
AERODYNAMIC AND ACOUSTIC PERFORMANCE OF EJECTORS FOR ENGINE-UNDER-THE-WING CONCEPTS
}

by U. von Glahn, J. Goodykoontz, and D. Groesbeck

Lewis Research Center

Cleveland, Ohio 44135

TECHNICAL PAPER proposed for presentation at Sixth Aircraft Design, Flight Test and Operations Meeting sponsored by the American Institute of Aeronautics and Astronautics Los Angeles, California, August $12-14,1974$ 


\title{
AERODYNAMIC AND ACOUSTIC PERFORMANCE OF EJECTORS FOR ENGINE-UNDER-THE-WING CONCEPTS
}

\author{
by U. von Glahn, ${ }^{1}$ J. Goodykoontz, ${ }^{2}$ and D. Groesbeck ${ }^{2}$ \\ V/STOL and Noise Division \\ Lewis Research Center \\ National Aeronautics and Space Administration \\ Cleveland, Ohio
}

\begin{abstract}
Subsonic thrust augmentation, exhaust plume velocity contours and acoustic characteristics of a smal1-scale, 6-tube mixer nozzle with ejector were obtained with and without a wing. Thrust augmentation up to 30 percent was achieved. Aerodynamic results showed that at a given location, greater downstream velocities are obtained with an ejector than with the baseline nozzle. Ejectors reduce high frequency noise; however, low frequency noise amplification also occurs. Acoustic reflections off the wing increase the noise level to a ground observer. With an ejector, the acoustic benefits of forward velocity may be significantly reduced compared with the baseline nozzle.
\end{abstract}

\section{INTRODUCTION}

The need to meet acceptable community noise standards for exhaust jets of all types of subsonic aircraft again has focused attention on ejector systems as a means of obtaining jet and core noise suppression. Early studies (refs. I to 4) indicated that substantial jet noise reductions for turbojet engines could be obtained with ejector systems. Typical results from these studies are shown in the schematic sketch of figure 1. It should be noted that the greatest noise reductions occurred at directivity angles of $140^{\circ}$ to $150^{\circ}$ measured from the inlet axis, with only about $2 \mathrm{~dB}$ noise reduction being achieved at the $90^{\circ}$ directivity angle. The latter angle, and those within about $30^{\circ}$ of it are those important in determining flyover and sideline noise for alrcraft. While the early studies showed the order of magnitude of noise reduction achievable with ejectors, the studies were of an ad hoc nature rather than of a parametric nature.

\footnotetext{
${ }^{1}$ Member, AIAA; Chief, Jet Acoustics Branch

${ }^{2}$ Aerospace Research Engineer
}

NASA TM X-71587

AIAA $74-950$ 
Ejector systems have the further ability to augment engine thrust, thereby enhancing the aircraft performance; consequent $1 y$, performance and weight penalties assoclated with other noise suppression devices that may be used in conjunction with an ejector system are minimized and may become more acceptable. Thrust augmentation is maximized for static conditions (i.e., zero forward speed) and, with fixed geometry, decreases rapidly with forward speed. The potential for maintaining some thrust augmentation at forward speeds associated with takeoff, however, appears possible by considering variable geometries for the ejector inlet and exhaust. Alternately, the ejector system could be retracted for cruise operation.

For future subsonic conventional takeoff and landing (CTOL) aircraft utilizing usual engine-under-the-wing (UTW) installations, ejectors with suitable acoustic linings can be used to reduce jet noise. For a CTOL nozzle-ejector configuration, the amount of exhaust noise redirection by the wing toward the ground as well as forward velocity effects on reducing configuration noise levels are of interest for design and noise-performance tradeoff purposes. For a CTOL application, it should be kept in mind that thrust augmentation with simple ejectors is not readily achieved during most of the takeoff due to the high takeoff speeds of CTOL aircraft.

For future short takeoff and landing (STOL) aircraft concepts utilizing an externally blown flap (EBF) with an engine-under-the-wing installation, the jet velocity decay rate and pattern prior to the impingement of the exhaust flow on the flap system becomes important to noise abatement. The interaction noise caused by the exhaust fet impingement on the flap surfaces can be lowered for EBF-UTW configurations by reducing the jet impingement velocity on the flaps. However, the ejector exhaust plane for such installations is generally located quite close to the flap system so that reductions in fet velocity decay rate due to the ejector would cause the exhaust jet to impinge on the flaps with a higher velocity than without an ejector. This could result in greater interaction nofse. However, as in the case of CTOL nozzleejector configurations, the initial jet nolse levels due to mixing can be reduced by suitable acoustic lining of the ejector walls (ref, 5)。 FInally, because of the relatively low takeoff speeds of STOL aircraft, an ejector can continue to augment the engine thrust for such aircrafi throughout the takeoff and initial climb phases. Consequently, the overall system noise, contributed by the nozzle exhaust flow, ejector and wing-flap conflguration should be determined with forward velocity in order to evaluate tradeoffs between noise and performance of STOL nozzle-ejector systems.

This report will first provide subsonic aerodynamic data on the effects of ejector geometry on the flow field of a sma11-scale 6-tube mixer nozzle, with and without considerations of forward speed. Sratic 
thrust augmentation data are presented for a number of ejector geometries from which several were selected for more detailed aerodynamic studies. The aerodynamic data are presented in terms of flow field (constant Mach number contour plots), velocity profiles at selected downstream axial stations, and peak axial velocity decay plots and correlations. Implications of forward speed effects on thrust augmentation associated with ejector systems are discussed briefly.

Acoustic data then are presented for selected ejector configurations, with and without forward velocity, for engine-under-the-wing CTOL configurations. Recent large-scale model and engine ejector data obtained in NASA STOL-EBF programs that are pertinent to the present study are discussed briefly. The CTOL-UTW acoustic data are compared with acoustic data previously published (ref. 6) for engine-over-thewing (OTW) CTOL configurations using ejectors.

\section{APPARATUS AND PROCEDURE}

\section{Facilities}

The static test stand and associated equipment used in the present work to obtain static thrust and jet velocity decay measurements are described in reference 7. The effect of forward velocity on jet decay was studied in the Lewis $6 \times 9$ foot subsonic wind tunnel described in reference 8 . A photograph of an ejector installation in this wind tunnel is shown in figure 2(a). A 13-1nch diameter free jet, described in reference 9, was used to obtain forward speed effects for the acoustic tests. Free jet velocitles from 0 to 175 feet per second were used in the present work. A photograph of the ejector with wing installed in the free jet is shown in figure $2(b)$.

Sound data for the small-scale models were taken with 0.5 -inch condenser microphones placed on a 10-foot radius circle centered at the nozzle exiţ. The microphone horizontal plane and jet centerline were located $12 \frac{3}{4}$ feet above ground level. The sound data were analyzed by a $1 / 3$ octave band spectrum analyzer. The analyzer determined sound pressure level (SPL) spectra referenced to 0.0002 microbar. Overall sound pressure levels (OASPL) were computed from the SPL data. Herein, no correctlons are made to the data for ground reflections. Most of the cancellations and reinforcements in the small-scale model acoustic data occur at much lower frequencles than the peak noise and are not pertinent to the present study.

Large-scale model acoustic data with an 8-lobed mixer nozzle with and without an ejector and with and without a wing were obtained in the cold-flow rig described in reference 10 . 


\section{Configurations}

A six-tube mixer nozzle was used as the baseline nozzle and had a total area equivalent to a 2.28-inch diameter, $D_{T}$, single nozzle. A sketch of this nozzle, taken from reference 8 , is shôn in figure 3. Ejector inside diameters of $5 \frac{1}{2}$ and 6 inches were used. The location of the ejector inlet lip was varied from 2 inches upstream to 4 inches downstream of the nozzle exhaust plane. Ejector length-to-nozzle-equivalent-diameter ratios, $\mathrm{L}_{\mathrm{T}} \mathrm{D}_{\mathrm{T}}$, of $2.94,4.4,6.6$, and 13.2 were used for most of the thrust augmentation and velocity decay studies. Only the $5 \frac{1}{2}$ inch diameter ejector with an $L / D_{e}$ of 2.94 was used in the acoustic studies. The acoustic data, on the basis of the aerodynamic work, was obtained at two axial positions of the ejector lip located $7 / 8$ inch upstream of the nozzle exhaust plane (hereinafter called "forward position") while the second position had the ejector Iip located $1 \frac{5}{8}$ inches downstream of the nozzle exhaust plane (hereinafter called "rearward position"). Placement of the baseline and ejector nozzles relative to the wing used to simulate a CTOL engine-under-the-wing configuration are shown in figure 4 .

Nozzle pressure ratios from 1.15 to 2.3 were used. The total temperature of the jet flow was a nominal $520^{\circ} \mathrm{R}$.

Large-scale model acoustic data were obtained with the 8-lobed mixer nozzle and wing described in reference 10. Individual ejector shrouds were attached to each nozzle lobe as shown in figure 5. Each ejector was acoustically lined with $1 / 2$ inch thick Scottfelt having an absorption coefficient near 1.0. Data were taken with nozzle pressure ratios from 1.3 to 1.7 at a nominal jet flow temperature of $520^{\circ} \mathrm{R}$.

\section{Thrust Augmentation}

The thrust augmentation values of the ejector system used herein are shown in figures 6 and 7 . The data shown are for the $5 \frac{1}{2}$ inch inside diameter ejector. The larger 6-inch inside-diameter ejector showed similar data trends with an augmentation of about 9 percent greater than that obtained with the smaller diameter ejector. Because the overall ejector size for aircraft use is important from considerations of external drag, only the smaller diameter ejector was studied extensively, both aerodynamically and acoustically. Details of the thrust augmentation characteristics are given in the following sections.

Effect of ejector length. - Maximum thrust augmentation was obtained with ejectors having an $\mathrm{L} / \mathrm{D}_{\mathrm{T}}$ ratio of about $6.6(\sim 15 \mathrm{in}$. ejector length). With $L / D_{T}$ ratios of about 2.94 and 13.2 , the augmentation was less by about 15 and 40 percent, respectively, from the peak value. In 
the case of the shortest ejector, the reduced augmentation was probably due to incomplete filling of the ejector with the flow induced by the pumping action of the jets. With the longer ejectors, the internal drag caused by the flow on the wall reduced augmentation. On the basis of size considerations for practical use on afrcraft, however, the shortest ejector $\left(\mathrm{L} / \mathrm{D}_{\mathrm{T}}=2.94\right)$ was selected for all the acoustic studies. Aerodynamic studies involving mixing considered primarily $L / D_{T}$ values of 2.94 and 4.4 .

Effect of ejector inlet position. - The effect of ejector inlet position on static thrust augmentation is shown in figure 6. The data shown are for a pressure ratio of 1.87. A maximum augmentation occurs when the ejector inlet lip is located about $1 \frac{5}{8}$ inches downstream of the nozzle exhaust plane. The lower thrust agumentation values with forward positions of the ejector inlet appears to be due to flow restrictions caused by the proximity of the ejector walls to the individual nozzles and the nozzle centerbody.

On the basis of the data shown in figure 6 , two inlet positions were selected for further aerodynamic and acoustlc studies. These inlet positions were $7 / 8$ inch upstream of the nozzle exhaust plane and $1 \frac{5}{8}$ inches downstream of the nozzle exhaust plane. The latter position produced the maximum thrust augmentation; however, because of the open space between the nozzle and ejector inlet, it appeared reasonable to expect noise from the exhaust flow to leak to the sideline and to the forward quadrant. On the other hand, the selected forward position of the ejector, while still providing substantial thrust augmentation, could help to shield observers at the sideline from the jet noise.

Effect of nozzle pressure ratio.- The effect of nozzle pressure ratio on thrust augmentation for two ejector inlet locations and two ejector lengths is shown in figure 7. The augmentation is seen to decrease with increasing pressure ratio until near choking (PR, 1.89); thereafter the trend is toward a slow recovery in augmentation with increasing pressure ratios. In the rearward inlet position the long ejector has somewhat better augmentation, by up to 3 percentage points, than the short ejector. In the forward location, the short ejector performs better at the lower pressure ratios than the long ejector; however, at pressure ratios greater than 1.5 the trend reverses. With a given ejector length, the rearward location of the ejector yields about 7 percentage points more thrust augmentation than the forward location. Exceptions are noted at very low pressure ratios $(\sim 1.4)$ where, depending on the ejector length, both smaller and greater percentage points are noted.

Effect of forward velocity on thrust augmentation.- Currently the effect of forward velocity on ejector thrust augmentation is not well understood. Most analytical approaches consider only well-mixed flow at the ejector exhaust plane, i.e., a uniform velocity profile. Mixer nozzles with practical short length ejectors, however, may not yield a uniform profile, as is the case for most of the present configurations. 
In an effort to assess the effect of forward velocity on the performance of ejectors used herein, an empirical modification of the method given in reference 11 was applied. The following equations, taken from reference 11 , were modified and rewritten in the present nomenclature. The thrust augmentation is given by:

$$
\frac{\Delta T}{T}=\frac{U_{e}}{U_{j}}\left(\frac{U_{e}}{U_{j}}-\frac{U_{o}}{U_{j}}\right) \frac{A}{a}+\frac{U_{o}}{U_{j}}-1
$$

where

$$
\frac{U_{e}}{U_{j}}=n\left(\frac{1}{2-\beta}\left\langle\left(\frac{a}{A}\right)^{2} \beta^{2}+(2-\beta)\left[\frac{a}{A}\left(2+\beta \frac{a}{A}\right)+\left(\frac{U_{o}}{U_{j}}\right)^{2}\right]\right\}^{\frac{l}{2}}-\beta \frac{a}{A}\right)
$$

and

$$
B=\frac{1-2 \frac{a}{A}}{\left(1-\frac{a}{A}\right)^{2}}
$$

The term $\eta$ is a correction parameter that is calculated from experimental data obtained from the static (zero forward speed) operation of the ejector configuration. This term is assumed to account for nonuniformity of the ejector exhaust velocity profile and the effect of ejector inlet location relative to the nozzle exhaust plane. Theoretically, $U / U_{j}$ calculated from equations (1) and (2) should be the same when $U / f, j$ is zero. Experimentally, however, the two values are different when the measured thrust augmentation values are used in equation (1). The n-parameter is defined as:

$$
n=\frac{(2-\beta)\left[\left(\frac{T+\Delta T}{T}\right)_{\text {meas }}\left(\frac{a}{A}\right)\right]^{\frac{1}{2}}}{\left.\int\left(\frac{a}{A}\right)^{2} B^{2}+(2-\beta)\left[\frac{a}{A}\left(2+\beta \frac{a}{A}\right)\right]\right]^{\frac{1}{2}}-\beta \frac{a}{A}}
$$


The predicted thrust augmentation degradation as a function of airspeed is shown in figure 8 for free stream velocities of 670 and $940 \mathrm{ft} / \mathrm{sec}$ for the two selected ejector locations used herein (forward location, 7/8 inch upstream of the nozzle exhaust plane and rearward location, $1 \frac{5}{8}$ inches downstream). The augmentation is seen to decrease rapidly with increasing airspeed. Zero augmentation is obtained for all ejector configurations in the range of 140 to $175 \mathrm{ft} / \mathrm{sec}$. This would indicate that the present ejector-nozzle configuration could perhaps maintain a very slight augmentation for STOL aircraft application at takeoff but would show a thrust loss, compared to the baseline nozzle, for CTOL aircraft with their relatively high takeoff and climb speeds compared to STOL aircraft. For the cruise condition, the present ejector should be retracted in order to avoid performance losses.

\section{AERODYNAMIC RESULTS}

The overall effects of flow conditions and nozzle geometry are detailed in Appendix A. In general, the effect of the ejector on the flow field was to delay the decay of the nozzle flow velocity downstream of the ejector exhaust plane compared to that for the baseline mixer nozzle. Forward velocity also delayed the decay of the jet velocity. In the case of the forward ejector position, poor mixing within the ejector was evidenced by the markedly differing velocity contour maps when comparing the contours taken in the tube-centerline plane with those taken in the mid-plane between the tubes (fig. 27). With the ejector in the rearward position, much better mixing (fig. 28) was observed than with the ejector in the forward position.

In the following sections, specific flow field characteristics of the ejector configurations are discussed in terms of radial profiles of velocity and peak axial velocity decay.

\section{Radial Profiles of Velocity}

Static flow conditions.- Radial profiles of velocity in terms of local Mach number and radial distance measured from the nozzle centerline are shown in figure 9 in the tube centerline plane. The data shown are for ejector lengths of 6.7 and 10 inches and both forward and rearward ejector inlet positions. The profiles are shown at axial stations of $: X / D_{T}=5$ and 7 . "These stations are of interest for STOL-EBF underthe-wing application. Also shown, for comparison, are the profiles for the baseline nozzle. "In general, the radial profiles of velocity with the ejector are substantially independent of ejector position and length at each $\mathrm{X} / \mathrm{D}_{\mathrm{T}}$ station: At both stations the peak velocity occurs at a somewhat greater radial distance from the nozzle centerline due to the 
jet flow attachment to the ejector walls (Coanda effect). At the $\mathrm{X} / \mathrm{D}_{\mathrm{T}}=5$ station, as evident from the flow field contours, the peak velocity is greater with the ejectors than that for the baseline nozzle. It is also evident that at $\mathrm{X} / \mathrm{D}_{\mathrm{r}}=7$ the velocity profiles obtained with the ejectors and with the baseline nozzle are approaching similarity.

Comparisons of the radial profile of velocity in the centerline plane of a tube with that in the mid-plane between adjacent tubes is shown in figure 10 at $X / D_{T}=5$ and 7 for various ejector positions and lengths. Good circumferential mixing is indicated when the profiles in the two planes approach each other as in the case of figure 10(c) for the $\mathrm{X} / \mathrm{D}_{\mathrm{T}}=5$ station and all cases shown for the $\mathrm{X} / \mathrm{D}_{\mathrm{T}}=7$ station.

Sector velocity profiles in the radial planes at $\mathrm{X} / \mathrm{D}_{\mathrm{T}}=5$ and 7 are shown in figure 11 for the ejector geometries discussed in figure 10 . These plots summarize graphically the mixed flows associated with the present nozzle-ejector configurations.

Effect of forward velocity.- The effect of forward velocity on radial profiles of velocity for the 6.7 inch long ejector in both the forward and rearward position is shown in figure 12 for the tube centerline plane. Also shown, for comparison, are the profiles for the baseline nozzle. All data shown are for forward velocity Mach number of 0.26. It is apparent that at each respective axial station the velocity profiles are all quite similar. As in the static flow case, the peak velocity with the ejector configurations occurs at a somewhat greater radial distance from the nozzle centerline than that for the baseline nozzle.

In figure 13, a comparison is shown of the radial profiles of velocity for the ejector in the forward position at the $\mathrm{X} / \mathrm{D}_{\mathrm{T}}=5$ and 7 stations for static flow and with forward velocity. The increase in local velocities with forward velocity shown is the maximum obtained with the present configurations.

\section{Peak Velocity Decay}

The peak velocity decay for a multi-element nozzle is a function of the mixing characteristics of the jet flow with the ambient (static) or external flow conditions. The significant flow regimes for a mixer-type nozzle are shown in figure 14, taken from reference 8 . As indicated in the figure, three flow regimes are identified: that associated with the individual jets issuing from each individual element or nozzle of a mixer nozzle, that assoclated with the coalescing region where mixing of the jet flow from adjacent elements or nozzles occurs and finally the coalesced core flow where mixing from the individual nozzles has been completed and 
a single large diameter jet flow has been established. The parameters shown in figure 14 and the equations for predicting the various flow regions are detailed in reference 8 . The parameters $U / U$ and $X\left(C_{n} D_{e} \sqrt{1+M_{j}}\right)^{-1}$ in figure 14 are taken from reference 8 and apply. for amblent static flow conditions.

With forward velocity, the peak axial velocity at a given axial station is greater with forward velocity than for the static condition, as already discussed in the previous section on radial profiles of velocity and in reference 8 . For completeness in the present report, the baseline nozzle and ejector configuration peak-axial velocity decay characteristics and correlations will be summarized from references 8 , 9 , and 12 as follows.

In reference 8 it was shown that for the 6-tube mixer nozzle, the peak axlal velocity decay with and without forward velocity could be correlated by the following empirical relationships:

$$
\frac{U-U_{o}}{U_{j}-U_{o}} \sim\left[x\left(C_{n} D_{e} \sqrt{1+M_{j}}\right)^{-1}\right]^{b}
$$

where

$$
b=1+\frac{1}{3}\left[\left(\frac{U_{j}}{U_{o}}\right)^{2}-1\right]^{-1}
$$

Figure 15 was taken from reference 9 to illustrate the degree of correlation achleved using these relationships.

The peak axial velocity decay for the ejector configurations was also correlated using the preceding equations. Correlation of the peak axial velocity decay for the mixer nozzle with the ejector in the rearward position is shown in figure $16(\mathrm{a})$ for $M$ values of 0 and 0.26 . Shown in figure 16(b) are the data for the mixer nozzle with the ejector in the forward location. In general, these latter data are somewhat higher than both the predicted values from the correlation equations and those with the ejector in the rearward location. The data with the ejector in the forward location appear shifted to the right on the abscissa. It is possible that, in the forward location of the ejector, the flow interaction of the jat flow with the ejector induced flow, $\mathrm{U}_{\mathrm{e}}$, causes a pseudo-forward velocity effect. Correlation would then require consideration of a term $U_{e j} / U_{j}$. much like the $U_{s} / U_{c}$ term for a bypass nozzle (ref. 8). Such an approach, however, is beyond the scope of the present work. 
In summary, the effect of forward velocity on the decay of jet exhaust flow is to extend the jet flow fleld in an axial direction. Except in the jet core flow region, this causes the local peak velocity at a given downstream location, measured from the jet exhaust plane, generally to be greater with forward velocity than that with static external flow. In addition, with forward velocity, a given velocity in the flow field is obtained at a smaller radial distance from the nozzle centerline than that with static flow.

\section{ACOUSTIC RESULTS}

General

The spectral characteristics of the various nozzle-ejector configurations with and without a wing are detailed in Appendix $B$. The nozzle-alone acoustic data are intended to serve as a base from which to judge the effect of the wing on ejector noise.

From these data, it is apparent that the spectral distribution for each nozzle-alone configuration is substantially independent of directivity angle from $60^{\circ}$ to $140^{\circ}$ as well as forward velocity. At $160^{\circ}$, the characteristic shift in the peak SPL location to a lower frequency occurs. This shift is not as evident for the ejector configurations as it is for the mixer nozzle because of the low frequency noise amplification caused by the Interaction of the jet flow with the ejector surface.

In general, the data trends discussed for the nozzle-alone data also apply to the nozzle-wing configurations. Except for the low frequency SPL data with the 6-tube mixer nozzle and wing, the data were independent of directivity angle $( \pm 2 \mathrm{~dB})$, as were the nozzle-alone data. The 6-tube mixer nozzle with wing showed an increase in noise level at low frequencies that varied with directivity angle. The maximum increases in SPL occurred at $60^{\circ}$ to $90^{\circ}$. This increase in SPL is attributed to jet-surface interaction noise at the trafling edge of the wing and surface scrubbing by the jet flow.

For consideration of aircraft $f$ lyover and sideline noise, the acoustic data at $60^{\circ}$ to $140^{\circ}$ are of more interest than that at $160^{\circ}$; consequently, upcoming acoustic data comparisons between configurations will not include the $160^{\circ}$ spectral data. Furthermore, because the spectral data in the range of directivity angles from $60^{\circ}$ to $140^{\circ}$ are substantially independent of directivicy angle, the comparisons will be made at the $90^{\circ}$ angle except as noted. In Appendix B, these data are emphasized by the solid curve through the $90^{\circ}$ data points.

The acoustic data will now be discussed in three parts: (1) nozzlealone data with and without the ejector, (2) nozzle-ejector data in the 
presence of a wing and (3) comparisons of data taken with and without a wing.

All data used, except where noted, is with a nominal jet velocity of $840 \mathrm{ft} / \mathrm{sec}$ and forward velocities of 0 and $175 \mathrm{ft} / \mathrm{sec}$.

Nozzle Alone

Comparison of configuration spectra.- The SPL spectra for the various configurations are compared at the $90^{\circ}$ directivity angle in figure 17 (a) for static conditions and in figure 17 (b) with forward velocity. The data are shown plotted in terms of SPL as a function of frequency in order to illustrate clearly the differences in SPL magnitudes for the various configurations. It is evident from these data that the noise level in the frequency range from 200 to 6300 hertz is greatly increased when the ejectors were used compared with that for the baseline nozzle. These increases in noise level amounted to as much as $16 \mathrm{~dB}$ and only second-order differences in the SPL spectral distribution were noted for the two ejector positions. At frequencies above 8000 hertz, the noise level was reduced by the use of ejectors compared with the baseline nozzle. The noise reductions were greater with the ejector in the rearward position ( $5 \mathrm{~dB}$ at 20000 hertz) than with it in the forward position $\left(2 \frac{1}{2} \mathrm{~dB}\right.$ at 20000 hertz):

The SPL spectra with forward velocity (fig. 17(b)) show similar trends for the various configurations as those with zero forward velocity. However, the SPL differences between the ejector configurations and the baseline nozzle increased. This indicates that the ejector configurations tested did not follow a 6-power law with relative velocity, $U_{j}-U_{0}$, as is the case for conical and mixer nozzles (ref. 9).

To illustrate this point, the $\triangle S P L$, defined as the difference between the statically measured SPL and that measured with forward velocity, is shown in figure 17 (c) as a function of frequency for the baseline nozzle and the two ejector configurations. The baseline nozzle has a broadband reduction in jet noise of $6 \mathrm{~dB}$ with a forward velocity of $175 \mathrm{ft} / \mathrm{sec}$. ThIs represents a 6-power reduction in jet noise with relative velocity, $U_{j}-U_{0}$.

With the ejector in the forward position the low frequency noise is reduced by the 6-power of the relative velocity, $U_{i}-U_{0}$, or about $6 \mathrm{~dB}$ (fig. $17(\mathrm{c})$ ). This reduction in jet noise due to forwarg velocity is the same as that for the nozzle alone. Consequently, it is surmised that the low frequency noise is generated downstream of the ejector exhaust plane. The high frequency noise is reduced only about $3 \mathrm{~dB}$. This noise appears to be generated within the ejector and is reduced by a modification of the induced flow by forward velocity rather than the for- 
ward velocity itself. Although the induced flow was not measured locally within the ejector, the effect of forward velocity on jet noise at high frequencies can be estimated by use of the 4-power of the relative velocity, $U_{j}-U_{0}$.

With the ejector in the rearward position, the effect of forward velocity on reducing the configuration noise was much less than that obtained with the ejector in the forward position. In the middle frequencies of 1250 to 5000 hertz substantially no reduction in noise was obtained with forward velocity. At both higher and lower frequencles, the reduction in noise with forward velocity was less than $3 \mathrm{~dB}$

(fig. 17(c)). From these results it appears that in the rearward position all the jet noise is generated within the ejector; consequently the effect of forward velocity is primarily to alter the induced flow. The latter then appears to determine the configuration noise level rather than the relative velocity. In the low and high frequency bands, an effective 3-power for the relative velocity can be used to predict the effect of forward velocity on the configuration noise level.

The low frequency noise amplification shown in figure 17 by the ejector configurations appears to be caused by an interaction of the jet flow with the ejector internal surfaces and trailing edge noise at the ejector exhaust plane. In this respect, the noise amplification is very similar to that noted with engine over-the-wing installations (ref. 13). The high frequency noise attenuation noted for figure 17(a) is also characteristic of such installations. Thus, the ejector, in a general sense, can be considered a three dimensional acoustic shield for the jet noise whereas the engine over-the-wing concept discussed in reference 13 is essentially a two dimensional acoustic shield for jet noise.

It was shown in reference 13 that low frequency noise amplification decreased with an increase in model scale. Unpublished largescale model acoustic data obtained with individual ejector shrouds placed around the lobes of the 8-tube multilobe nozzle of reference 10 tend to confirm this for the ejector case. In figure 18 typical spectra are shown for the nozzle configuration of reference 10 with and without an ejector. Low frequency noise amplifications, of the order of $5 \mathrm{~dB}$ are noted at frequencies less than 3000 hertz and noise reductions up to about $10 \mathrm{~dB}$ compared to the nozzle alone were measured at 20000 hertz. Similar data trends are reported in reference 14 in which spectral data for a quiet $6: 1$ bypass ratio engine with and without an ejector were presented.

OASPL.- The OASPL values associated with the nozzle-alone configurations are also included in Appendix $B$ for the directivity angles noted. In general, use of the ejectors shift the peak OASPL from $160^{\circ}$ obtained with the baseline 6 -tube mixer nozzle to $120^{\circ}$ to $140^{\circ}$. In addition, the 
use of ejectors increased the overall noise level at $60^{\circ}$ compared with the baseline nozzle. Forward velocity also tended to shift the peak OASPL with the ejector configurations toward lower directivity angles (away from jet axis) with the peak OASPL being measured near $120^{\circ}$ with forward velocity.

\section{Nozzle and Wing Configurations}

The variations of SPL with frequency for the ejector-wing configurations are shown in figure 19. The data shown are for a directivity angle of $90^{\circ}$ and with and without forward velocity. The baseline 6-tube mixer nozzle-wing data are shown for comparison with the ejectorwing data. The two ejector-wing configurations show substantially the same noise levels over the broadband frequency range of 300 to 20000 hertz at zero forward velocity. From 500 to 4000 hertz the mixer nozzlewing data are about 8 to $10 \mathrm{~dB}$ more quiet than with the ejector configurations. Above 5000 hertz the ejector-wing configurations were more quiet than the baseline nozzle-wing configuration due to the high frequency noise shielding obtained with the ejectors. At frequencies below 500 hertz, the low frequency noise amplification for the baseline mixer nozzle with wing yielded noise levels similar to those for the ejectorwing configurations.

With forward velocity, spectral trends similar to those discussed for the nozzle-alone configurations also were observed with the nozzlewing configurations. Consequently, no significant noise relief was afforded the ejector-wing configurations by forward velocity.

Large-scale model spectral data obtained with an 8-1obed mixer nozzle and wing configuration (ref. 10) are shown in figure 20. Also shown are unpublished data for the same configuration with an ejector on each lobe. For the data of figure $20,60^{\circ}$ deflected flaps were used. It is apparent that low frequency noise amplification and high frequency noise shielding were obtained with the ejector-wing configuration when compared with the nozzle alone-wing configuration.

Spectral data obtained with a quiet 6:1 bypass ratio engine with and without an ejector utilizing an UTW configuration (ref. 14) showed trends similar to those for the small-scale and large-scale model data.

\section{Comparison of Spectra With and Without Wing}

Small-scale models.- Comparisons of the SPL spectra for the ejectors and wing with the ejector-alone data are shown in figure 21 . The. data are plotted in terms of SPL as a function of frequency for a directivity angle of $90^{\circ}$ and with and without forward velocity. The baseline 
6-tube mixer nozzle and wing data are also shown for comparison with those for the ejector configurations.

The data in figure 21 show that, with the small-scale models, the presence of the wing will increase the noise level by 1 to $3 \mathrm{~dB}$ over a broadband spectral range. This increase is caused by reflection of the jet noise by the wing surface. The low frequency noise amplification is increased generally more (2 to $3 \mathrm{~dB}$ ) than the high frequency noise component ( 1 to $2 \mathrm{~dB}$ ). The increases in noise due to acoustic reflections by the wing are independent of forward velocity.

Large-scale mode1.- A direct data comparison similar to that just shown for the small-scale model acoustic data cannot be made for the large-scale model data. The former data were obtained with zero flap deflection while the latter data were obtained with a 3-flap system deflected $60^{\circ}$ at the trailing edge of the third flap. Direct impingement of the jet flow on the flap surfaces caused an increase in the overall noise level and this interaction noise dominated in certain frequency ranges. It is of interest, however, to discuss briefly the differences in the overall noise levels with and without an ejector for such a configuration.

In figure 22 the SPI as a function of frequency is shown for the large-scale model data with and without an ejector and with and without a wing. It is apparent that the jet-flap interaction noise increases the lower frequency noise levels for both nozzle configurations. The increase is of the same order of magnitude, with a maximum increase of about $11 \mathrm{~dB}$. In the high frequency region (> 5000 hertz) the two nozzle configurations exhibit markedly different characteristics. Without the ejector, the SPL values near 5000 hertz appear to show the effect of acoustic reflections from the wing; i.e., broadband increases in noise level of about 2 to $3 \mathrm{~dB}$. At frequencles greater than 10000 hertz, the wing appears to have no effect on the sound pressure level. With the ejector, the SPL values near 5000 hertz again appear to be associated with acoustic reflections from the wing. At frequencies greater than 10000 hertz, the ejector provides some shielding of jet noise compared with the nozzle alone data. However, the amount and extent of jet noise shielding is considerably less in the presence of the wing than without it. For example, a maximum suppression of $4 \mathrm{~dB}$ is obtained with the ejector-wing configuration compared to the nozzle alone or nozzle-wing configurations, whereas without the wing, a maximum suppression of $10 \mathrm{~dB}$ is obtained with the ejector alone compared with the nozzle alone. Similarly, the initiation of noise suppression is moved from an initial 3000 hertz to 9000 hertz for the ejector by the presence of the wing. The failure to achieve good noise suppression with the ejector-wing configuration is believed due to the jet-flap interaction noise sources. It appears 1ikely that these noise sources provide a floor to the ejector noise suppression capability at high frequencles. In order to 
achieve the ejector noise suppression capability, a reduction of the jet-flap interaction noise floor is required. It would be expected that with the flaps retracted, the noise suppression capabilities of the ejector system could be achieved with only a 1 to $2 \mathrm{~dB}$ increase in noise level due to acoustic reflections from the wing, as shown by the small-scale model data, over that for the ejector-alone data.

In the engine-wing data of reference 14 acoustic data trends similar to those just discussed are evident.

\section{Comparison of Ejector Configurations in UTW and OTW Orientation}

The present study has been concerned with engine under-the-wing use of ejector systems. Reference 6 contains data obtained with the same mixer nozzle and ejectors in an engine over-the-wing installation (OTW). Comparisons of the sound pressure level as a function of frequency for both UTW and OTW orientation of the baseline mixer nozzle with and without ejectors are shown in figures 23 and 24 . The data shown are for a nominal jet velocity of $940 \mathrm{ft} / \mathrm{sec}$, a forward velocity of $175 \mathrm{ft} / \mathrm{sec}$ and a $90^{\circ}$ directivity angle. The forward velocity case was selected for this comparison since the configurations operate at about comparable thrust levels; i.e., the thrust augmentation is negligible for the ejector configurations permitting direct acoustic comparisons without compensating for thrust differences by jet velocity adjustments. The solid curves in the figures represent the respective nozzle-alone noise level. It is apparent that the OTW orientations are significantly less noisy than the UTW configurations. Both ejector-wing configurations indicate a large broadband reduction in noise level with the OTW orientation, whereas the baseline mixer nozzle-wing configuration shows little noise reduction at low frequencles but large reductions at high frequencies. It should be noted, however, that although larger noise reductions are achieved with the ejector OTW configurations than the baseline nozzle OTW configuration at low frequencies, the absolute sound pressure level values are higher for the ejector configurations than those for the baseline mixer nozzle configuration. In the frequency range from 500 to 5000 hertz the forward ejector position is about 4 to $6 \mathrm{~dB}$ louder than the baseline configuration. The rearward ejector position is about 6 to $10 \cdot \mathrm{dB}$ louder than the baseline configuration over the same frequency range. The greater SPL for the rearward ejector position is due to the small effect of forward velocity on the SPL for this ejector position, as discussed earlier. At high frequencies, the OTW configurations tend to approach substantially the same values of sound pressure level.

The differences in sound pressure level between the UTW and OTW configurations are shown in figure 25 where $\triangle S P L_{1}=S P L$
is plotted as a function of frequency. The data indicate that at ${ }_{\text {OTh }}$ 
low end of the frequency spectrum the ejector under-the-wing noise is about $5 \mathrm{~dB}$ louder than the over-the-wing installation. At the middle and high frequency portions of the frequency spectrum, the ejector UTW noise is about $8 \frac{1}{2} \mathrm{~dB}$ louder than the OTW configuration.

Much of the $\triangle S P L$ ( 2 to $3 \mathrm{~dB}$ ) at the lower frequencies can be attributed to the additional noise caused by acoustic reflections from the wing for the ejector UTW configuration. In the high frequency range, the $\triangle S P L_{T}$ is contributed mostly by jet noise shielding by the wing for the OTW orientation.

Data for the baseline mixer nozzle with wing data, shown by the solid curve in figure 25, indicates somewhat lower $\triangle S P L$ values at low frequencies to about $2 \mathrm{~dB}$ higher than the ejector configurations at 20000 hertz.

\section{CONCLUDING REMARKS}

The results from this small-scale model study lead to a number of observations discussed briefly in the following paragraphs. While the trends noted apply specifically to the models tested, it can be assumed, on the basis of limited data from other studies (refs. 1 to 4, 10 and 14) that similar trends, differing perhaps only in magnitude, apply generally to many ejector configurations.

Forward velocity is known to reduce the thrust augmentation obtained with ejectors. It is apparent from theoretical considerations that a variable geometry ejector perhaps could be designed to overcome the forward velocity deficiency. However, the complexity and weight of such an ejector may prove too great for its thrust advantages. An ejector could also be retracted for cruise to reduce the cruise drag penalties. This would require a nozzle design with a high flow coefficient and low cruise drag. Further aerodynamic work in this area is recommended together with proper considerations for the additional weight of such configurations in order to establish practical operational criteria for the use of ejector systems.

For the specific mixer nozzle and ejector configurations studied, the use of an ejector increased the local velocities at a given axial station compared to those with the nozzle alone. Also the radial extent or boundary of the exhaust jet was somewhat reduced at a given axial station when an ejector was used compared to that for the nozzle alone. These two effects of themselves did not appear to influence the noise level of the ejector-alone configurations. However, in the case of a STOL-UTW aircraft, an ejector can cause an increase in the jet-flap interaction noise when the higher velocity exhaust flow impinges on the 
deflected flap system. The increase in impingement velocity due to the use of an ejector is compensated for somewhat by a reduced flap flow-impingement area. The dominant effect will depend on specific nozzle-ejector flow. characteristics.

The effect of forward velocity on the noise level of a nozzleejector configuration is a function of the induced flow characteristics in the ejector. For the configurations tested, this was evidenced by the ejector inlet position relative to the nozzle exhaust plane. With the ejector in the rearward position (maximum thrust augmentation), the noise level was substantially independent of the relative velocity. With the ejector in the forward position (less than maximum thrust augmentation), the effect of relative velocity on noise was equal to that for the nozzle alone case at low frequencles and about one-half that for the nozzle alone at high frequencles. When the reduction of the noise level due to relative velocity is needed to achieve a given community noise level, a trade-off between noise and thrust augmentation may be required.

The ejector acts as a 3-dimensional noise shield in that the high frequencies of the jet are shielded but the low frequencies are amplified. The specific amounts of noise shielding and amplification depend on the configuration geometry. The ejector noise spectra appear to follow the trends of the 2-dimensional shielding discussed in reference 13 for CTOL-OTW applications in that the noise amplification becomes less with an increase in scale. However, because of the dimensional limitations involved in a practical propulsion design, this low frequency noise increase may still be a dominant factor.

The increase in noise level due to acoustic reflections from the wing in an UTW configuration, with and without forward velocity, generally was to be expected. It was not known, however, what influence the ejector might have. It appears that the high frequency noise, generally contained within the confines of the ejector, is not affected greatly by the presence of the wing $(\sim 1 \mathrm{~dB})$. The low frequency noise which can be assumed to be generated near or downstream of the ejector exhaust plane was increased by about $3 \mathrm{~dB}$ due to acoustic reflections from the wing surface.

Use of an acoustically lined ejector generally can reduce the jet mixing noise level within the ejector by significant amounts ( $\sim 5 \mathrm{~dB}$ ) at the middle and high frequencies. However, the jet flow interaction with the ejector walls may provide a floor so that the theoretical broadband noise reductions due to acoustic linings may not be attained.

Comparison of ejector configurations with OTW and UTW orientation leads to the conclusion that OTW installations are quieter. The difference in noise level spectra for the two orientations amounts to 
about $5 \mathrm{~dB}$ at low frequencles and $8 \frac{1}{2}$ at high frequencies. These reductions are with a forward velocity of 175 feet per second. The ejector in the forward position is quieter than that in the rearward position due to the noise reductions afforded by forward velocity.

NOMENCLATURE

(English units, except as noted)

A ejector exhaust area

a nozzle exhaust area

b velocity parameter, equation (6)

$C_{n} \quad$ nozzle flow coefficient

De single element diameter of a multitube nozzle

$\mathrm{D}_{\mathrm{T}} \quad$ equivalent nozzle diameter

L ejector length

M jet Mach number

$M_{0} \quad$ free stream Mach number

OASPL overall sound pressure level, dB

$\mathrm{P}_{\mathrm{N}} \quad$ nozzle upstream total pressure

$p_{0} \quad$ ambient static pressure

PR nozzle pressure ratio, $\mathrm{P}_{\mathrm{N}} / \mathrm{P}_{\mathrm{O}}$

SPL sound pressure level, dB re $2 \times 10^{-5} \mathrm{~N} / \mathrm{m}^{2}$

$\triangle S P L$ difference in sound pressure level without and with forward velocity, $\mathrm{dB}$

$\triangle S P L_{I}$ difference in sound pressure level between under-the-wing and over-the-wing nozzle installations, $\mathrm{dB}$

T nozzle thrust

$\Delta \mathrm{T} \quad$ thrust augmentation 


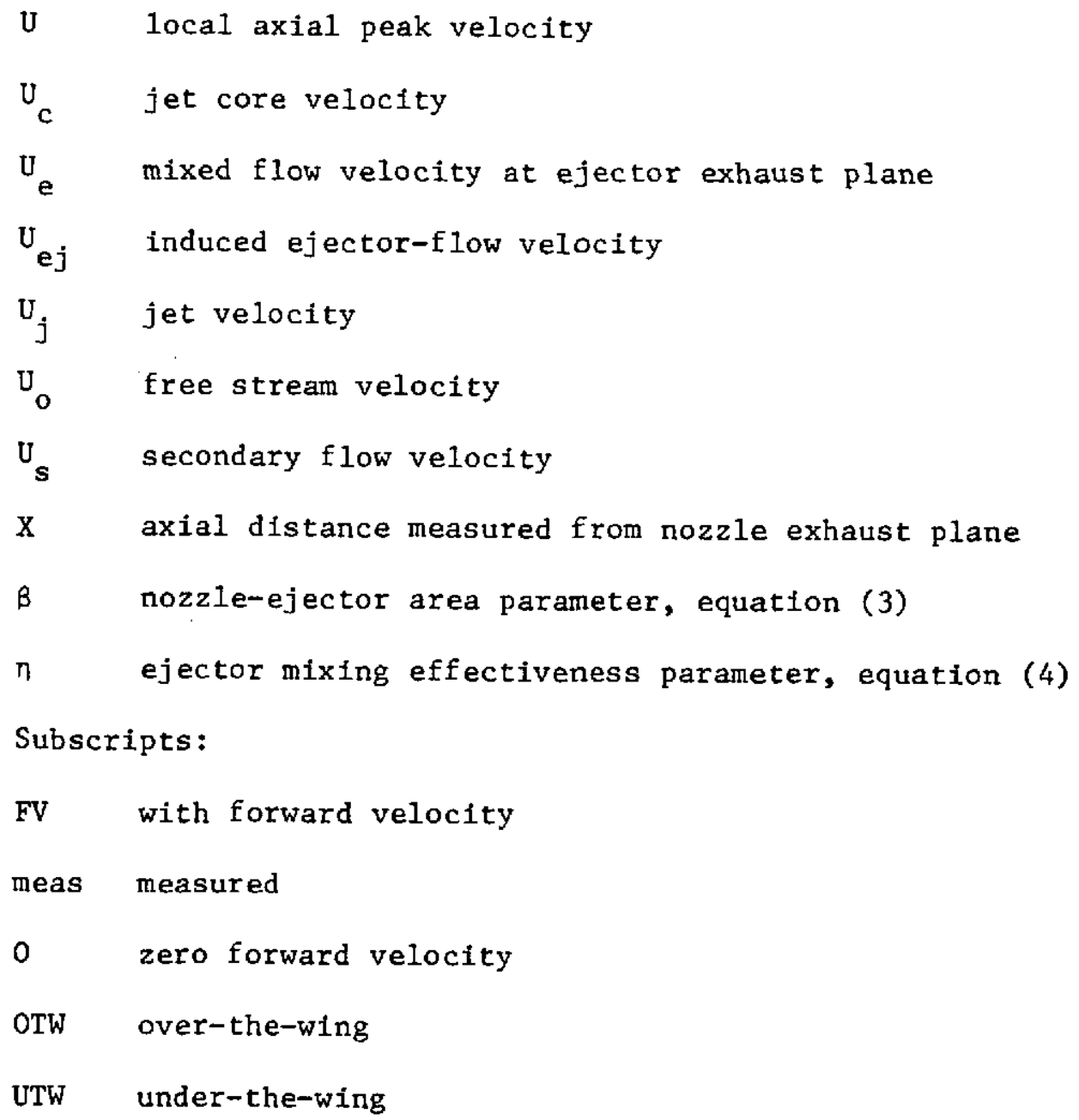


APPENDIX A

Jet Flow Field

The overall effects of flow conditions and nozzle-ejector geometry on the jet exhaust flow field are shown in figures 26 to 29 . Where appropriate, the 6-tube baseline nozzle flow field also is shown for comparison. The flow field data and curves shown in figures 26 to 29 are in terms of lines of constant Mach number plotted as a function of radial and axial distance measured from and along the overall pozzle centerline, respectively. All the ejector data are for the $5 \frac{1}{2}$ inch I.D. ejector and with a jet Mach number of 0.98 . The data trends shown are applicable to other jet Mach numbers included in the study.

Effect of ejector length.- With the ejector in the forward position, a change in the shroud length from 6.7 to 10 inches had a negligible effect on the flow-field velocity contours (fig. 26(a)). In the rearward ejector position, the same change in shroud length caused local increases in velocity (fig. 26(b)). For example, with the 6.7 inch ejector the $0.4 \mathrm{Mach}$ number contour line extended to the 20 inch station downstream of the nozzle exhaust plane; however, with the 10 inch ejector the same contour line extended to the 24 inch station. In a practical application for a STOL-EBF system, this reduced rate of the jet velocity decay could cause an increase in the jet-flap interaction noise since this noise source is a 6-power function of the flow impingement velocity on the flap (ref, 15)。

Effect of ejector inlet position.- The effect of ejector inlet position on the downstream flow field is shown in figures 27 and 28 . Also shown for comparison in the figure is the flow field for the baseline nozzle. In figures $27(\mathrm{~b})$ and $27(\mathrm{c})$. Mach number contour lines are shown with the ejector in the forward position for two survey planes: the tube centerline plane and the mid-plane between adjacent tubes of the nozzle. Comparison between the ejector configuration and the baseline nozzle in the centerline plane shows substantially no differences in the respective contour maps except near the ejector exhaust plane. Near this location, the ejector flow Mach numbers are somewhat higher than those for the baseline nozzle (fig. 27(a)). This effect can perhaps be attributed to an "airspeed" effect that the induced flow in the ejector has on the nozzle jet flow and which tends to reduce the rate of the jet velocity decay. The mid-plane flow contours (fig. 27(c)) show that near the ejector exhaust plane the velocity is less than onehalf that at the tube centerline, indicating poor mixing. However, downstream of the 22 inch station the flow appears we11-mixed and the contours in both planes are quite similar. 
The flow-field Mach number contours at the rearward ejector inlet postion are shown in figures $28(\mathrm{~b})$ and $28(\mathrm{c})$ for the previously mentioned survey planes. Comparison of the ejector flow contours on the tube centerline with those for the baseline nozzle (fig. 28(a)) show substantially no differences. The flow contours in the mid-plane between tubes indicates much better mixing than when the ejector was in the forward position. Well-mixed flow in both planes is apparent downstream of the 15 inch station.

Effect of forward velocity.- Flow-field contours with forward velocity were obtained with the 6.7 inch long ejector. These data are shown in figure 29 for both forward and rearward positions of the ejector. For comparison, the baseline nozzle flow-field contours are also included. The contours were obtained for a jet Mach number of 0.98 and a forward velocity Mach number of 0.26 . It is apparent that the contours with forward velocity are substantially independent of the ejector inlet position and about the same as those for the baseline nozzle; particularly for the case of the ejector in the rearward position. Comparison of the absolute values of the Mach number contour lines, with and without forward velocity, shows that forward velocity increases the local velocities at a given axial station. For example, at the 20 inches axial station, the local Mach number is about 0.4 for ambient flow conditions (figs. 27 and 28) whereas with forward velocity it is 0.5 (fig. 29). 


\section{APPENDIX B}

\section{Spectral Characteristics}

The spectral characteristics of the various nozzle configurations with and without a wing are presented in figures 30 to 35 in terms of SPL-OASPL as a function of frequency. The data include directivity angles from $60^{\circ}$ to $160^{\circ}$ measured from the nozzle inlet. All data were obtained with a nominal jet velocity of $840 \mathrm{ft} / \mathrm{sec}$ and forward velocities of 0 and $175 \mathrm{ft} / \mathrm{sec}$. The nozzle-alone data with and without an ejector serve as a base from which to judge the effect of the wing on ejector noise.

The noise levels of the 6-tube baseline nozzle and the ejector configurations are shown in figures 30 to 32 . The SPL spectra for the 6-tube mixer nozzle and ejector configurations with a wing are shown in figures 33 to 35 . Solid curves are drawn through the $90^{\circ}$ data in figures 30 to 35 to emphasize the spectra used for trend comparisons in the text. 


\section{REFERENCES}

1. Coles, W. D., Mihaloew, J. A., and Callaghan, E. E., "Turbojet Engine Noise Reduction With Mixing Nozzle-Ejector Combinations," TN 4317, 1958, NACA.

2. Coles, W. D., Mihaloew, J. A., and Swann, W. H., "Ground and InFlight Acoustic and Performance Characteristics of Jet-Aircraft Exhaust Noise Suppressors. TN D-874, 1971, NASA.

3. Clepluch, C. C., North, W. J., Coles, W. D., and Antl, R. J., "Acoustic, Thrust and Drag Characteristics of Several Full-Scale Noise Suppressors for Turbojet Engines," TN 4261, 1958, NACA.

4. North, W. J., and Coles, W. D., "Effect of Exhaust Nozzle Ejectors on Turbojet Noise Generation," TN 3573, 1955, NACA.

5. von Glahn, U. H., Gray, V. H., Krejsa, E. A., Lee, R., and Minner, G. L., "Jet Noise," Aircraft Engine Noise Reduction, SP-311, 1972, NASA, pp. 103-138.

6. von Glahn, U., Goodykoontz, J., and Wagner, J., "Nozzle Geometry and Forward Velocity Effects on Noise for CTOL Engine-Over-the-Wing Concept," TM X-71453, 1973, NASA.

7. McKinzie, D. J., Jr., and Burns, R. J., "Externally Blown Flap Trailing Edge Noise Reduction by Slot Blowing--A Preliminary Study," TM X-68172, 1973, NASA.

8. von Glahn, U., Sekas, N., Groesbeck, D., and Huff, R., "Forward Flight Effects on Mixer Nozzle Design and Noise Considerations for STOL Externally Blown Flap Systems," TM X-68102, 1972, NASA.

9. von Glahn, U., Groesbeck, D., and Goodykoontz, J., "Velocity Decay and Acoustic Characteristics of Various Nozzle Geometries with Forward Velocity," TM X-68259, 1973, NASA.

10. Goodykoontz, J. H., Wagner, J. M., and Sargent, N. B., "Noise Measurements for Various Configurations of a Model of a Mixer Nozzle - Externally Blown Flap System," TM X-2776, 1973, NASA.

11. Lissaman, P., and Harris, G., "The Mechanics of Ejector Thrust Augmentation," Ae TR-67-1, 1967, California Institute of Technology, Calif.

12. von Glahn, U. H., Groesbeck, D. E., and Huff, R. G., "Peak AxialVelocity Decay with Single-and Multi-Element Nozzles," TM X-67979, 1972, NASA. 
13. von Glahn, U., Groesbeck, D., and Reshotko, M., Geometry Considerations for Jet Noise Shielding with CTOL Engine-Over-the-Wing Concept," TM X-71562, 1974, NASA.

14. Samanich, N. E., Heidelberg, L. J., and Jones, W. L., "Effect of Exhaust Nozzle Configuration on Aerodynamic and Acoustic Performance of an Externally Blown Flap System with a Quiet 6:1 Bypass Engine," TM X-71466, 1973, NASA.

15. Dorsch, R. G., "Externally Blown Flap Research," TM X-71541, 1974, NASA. 


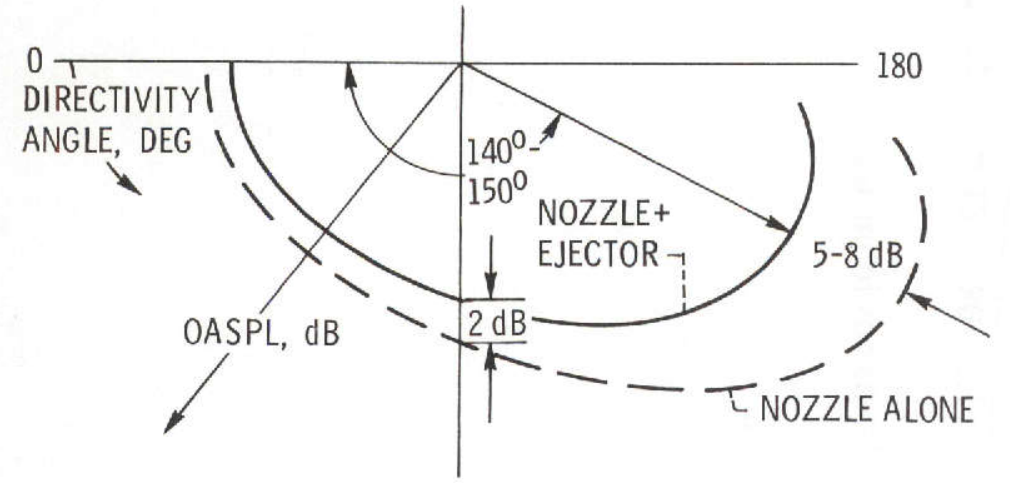

90

Figure 1. - Typical noise reduction obtained with ejector. Turbojet engine; subsonic flow; reference 1.

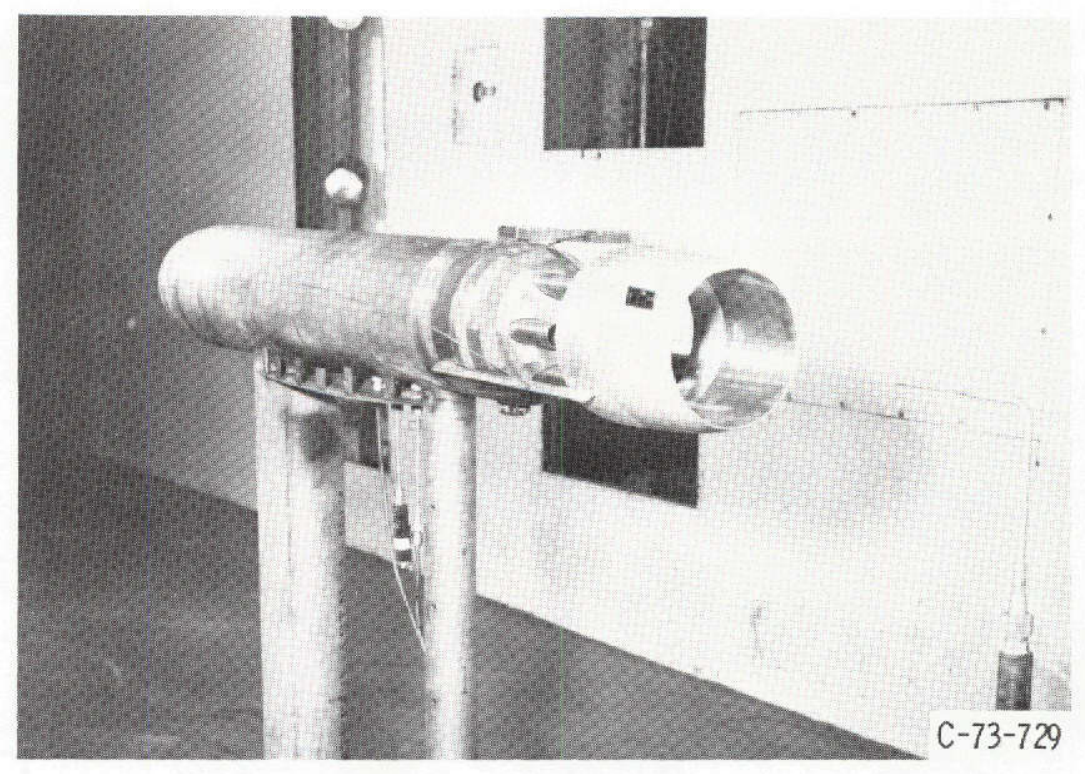

(a) 6-TUBE MIXER NOZZLE WITH EJECTOR INSTALLED IN 6X9 F00T WIND TUNNEL FOR AERODYNAMIC MEASUREMENTS WITH FORWARD VELOCITY.

Figure 2. - Photographs of model configurations.

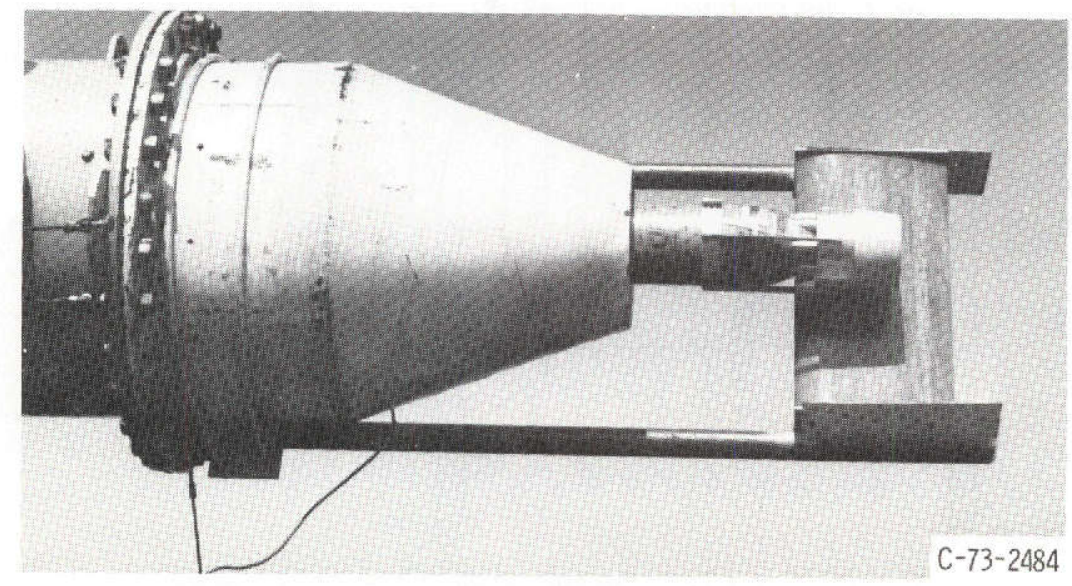

(b) EJECTOR-WING CONFIGURATION MOUNTED IN FREE JET.

Figure 2. - Concluded. 


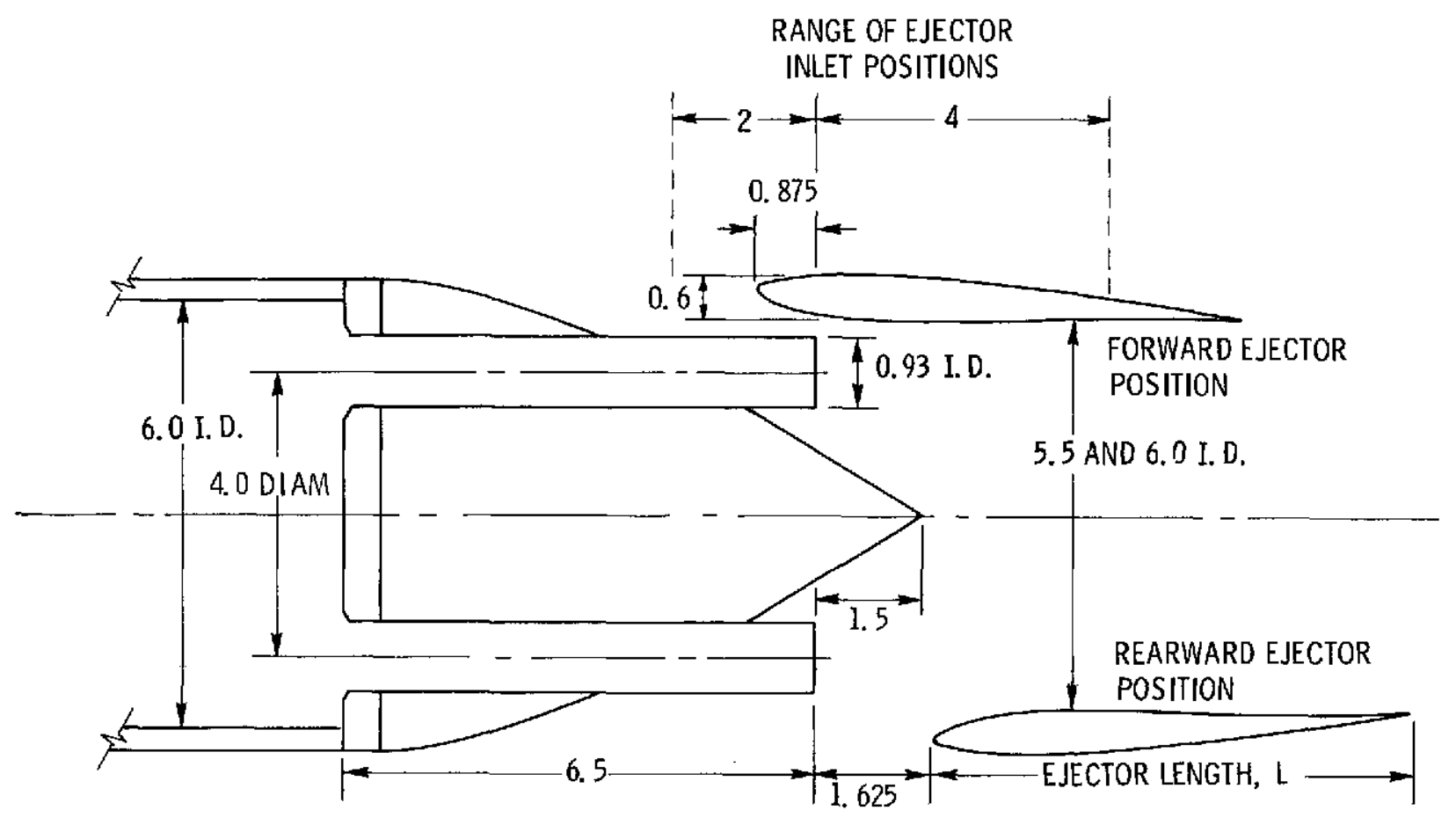

Figure 3. - 6-Tube mixer with and without ejector. All dimensions in inches. 


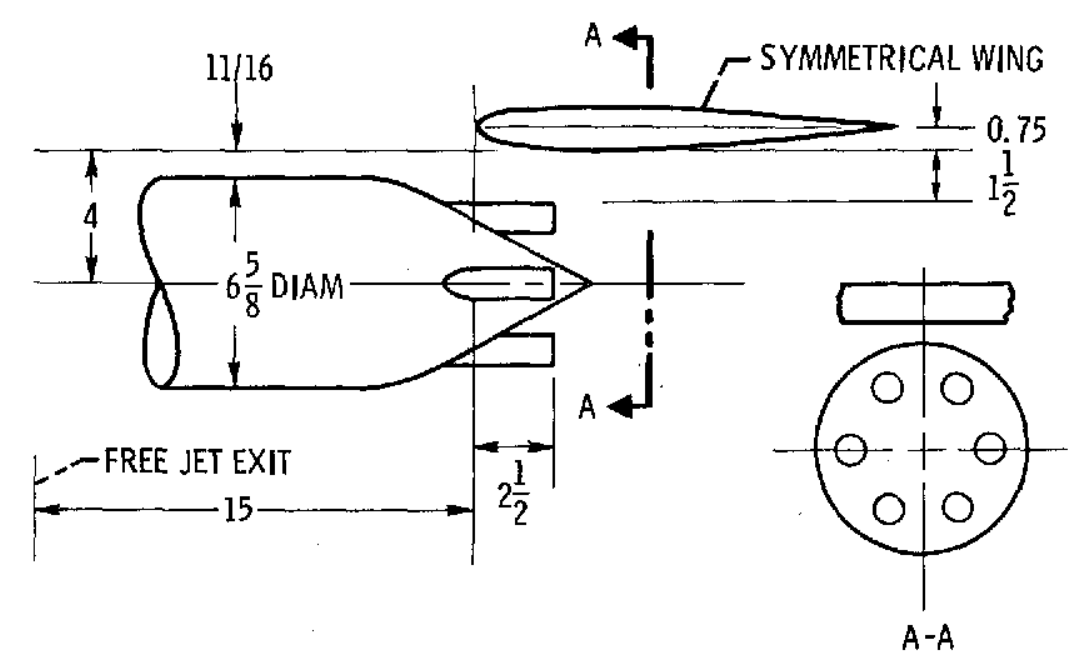

(a) BASELINE 6-TUBE MIXER NOZZLE.
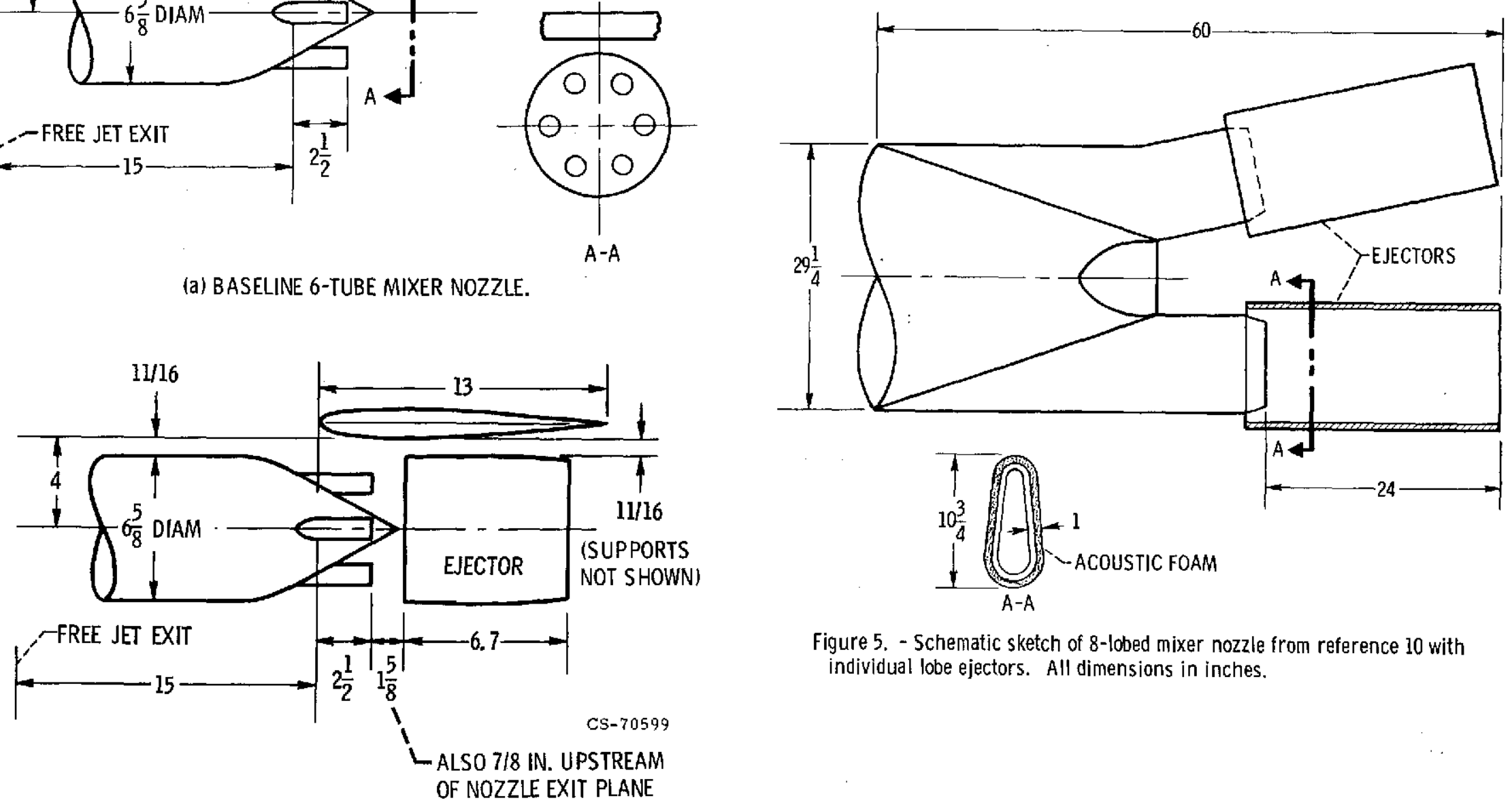

Figure 5. - Schematic sketch of 8-lobed mixer nozzle from reference 10 with individual lobe ejectors. All dimensions in inches.

(b) EJECTOR CONFIGURATIONS.

Figure 4. - UTW orientation of 6-tube mixer nozzle with and without ejector. All dimensions in inches. 
EJECTOR INLET POSITION FOR ACOUSTIC TESTS

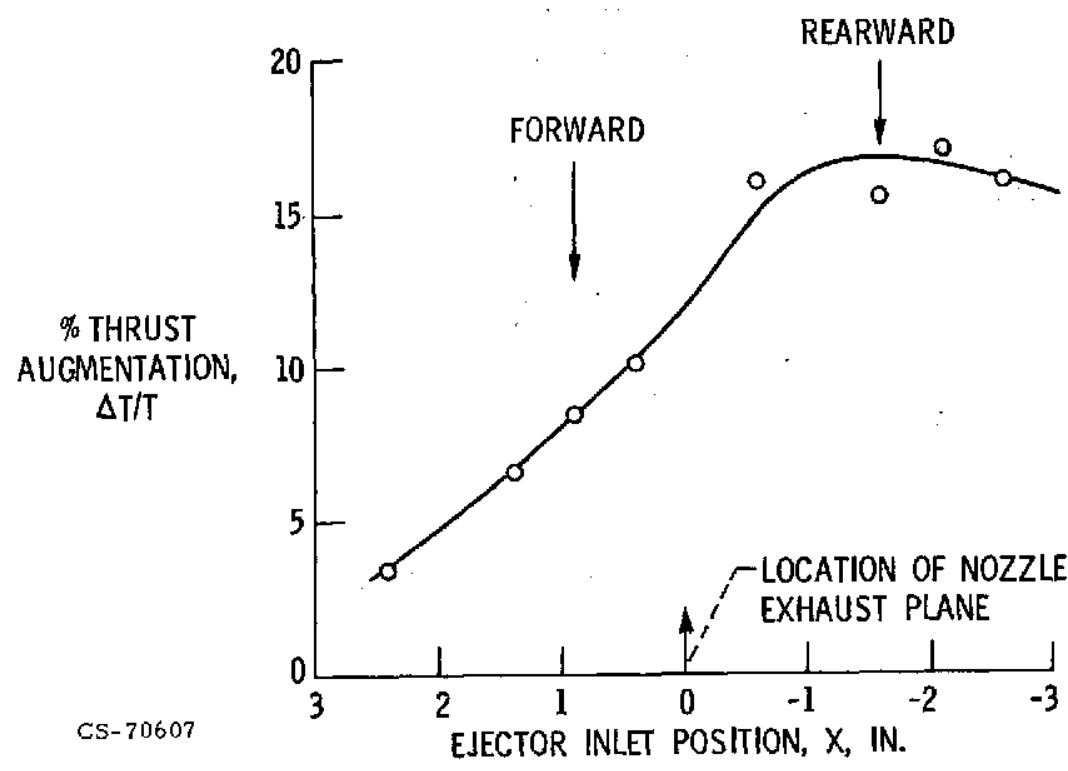

Figure 6. Effect of ejector inlet location on thrust augmentation. $P R, 1.87$; ejector length, 6.7 in.; ejector inside diameter, $5.5 \mathrm{in}$; L/DT, 294

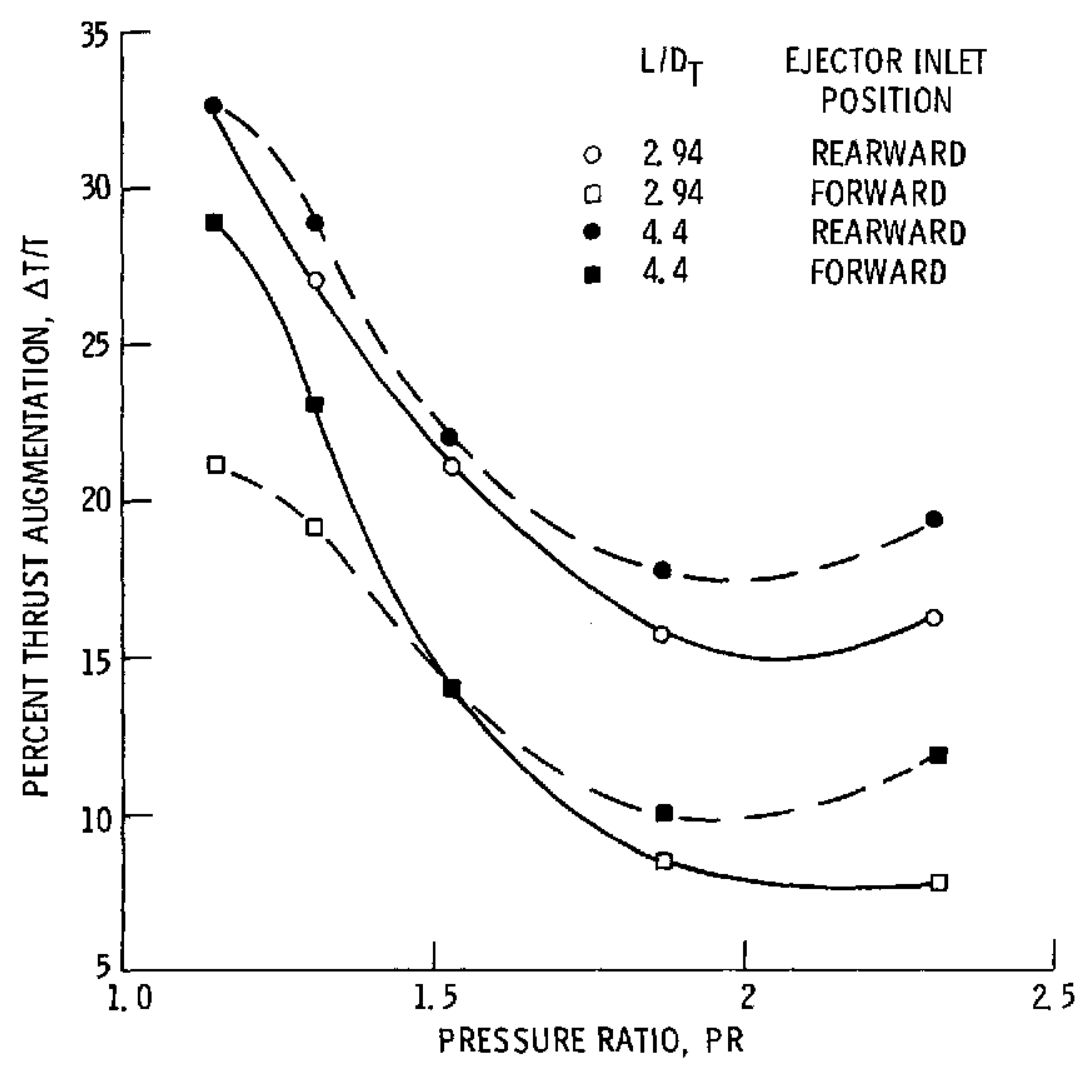

Figure 7. - Variation of thrust augmentation with nozzle pressure ratio. 


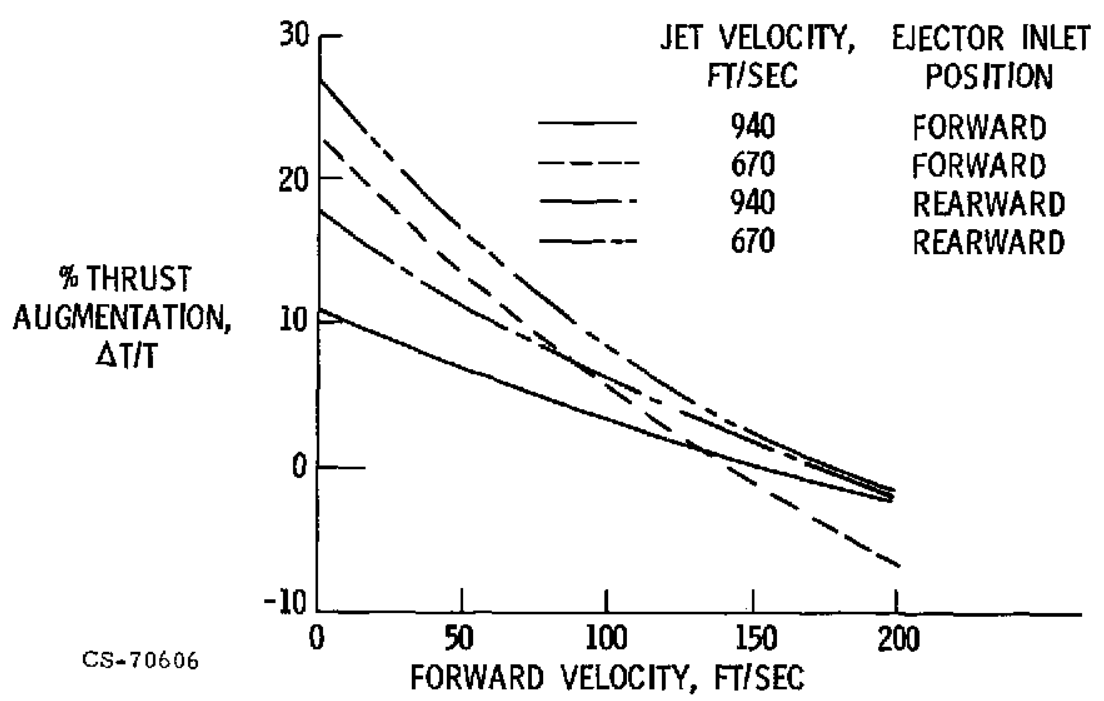

Figure 8. - Calculated airspeed effect on thrust augmentation. 6-Tube mixer nozzle with ejector.
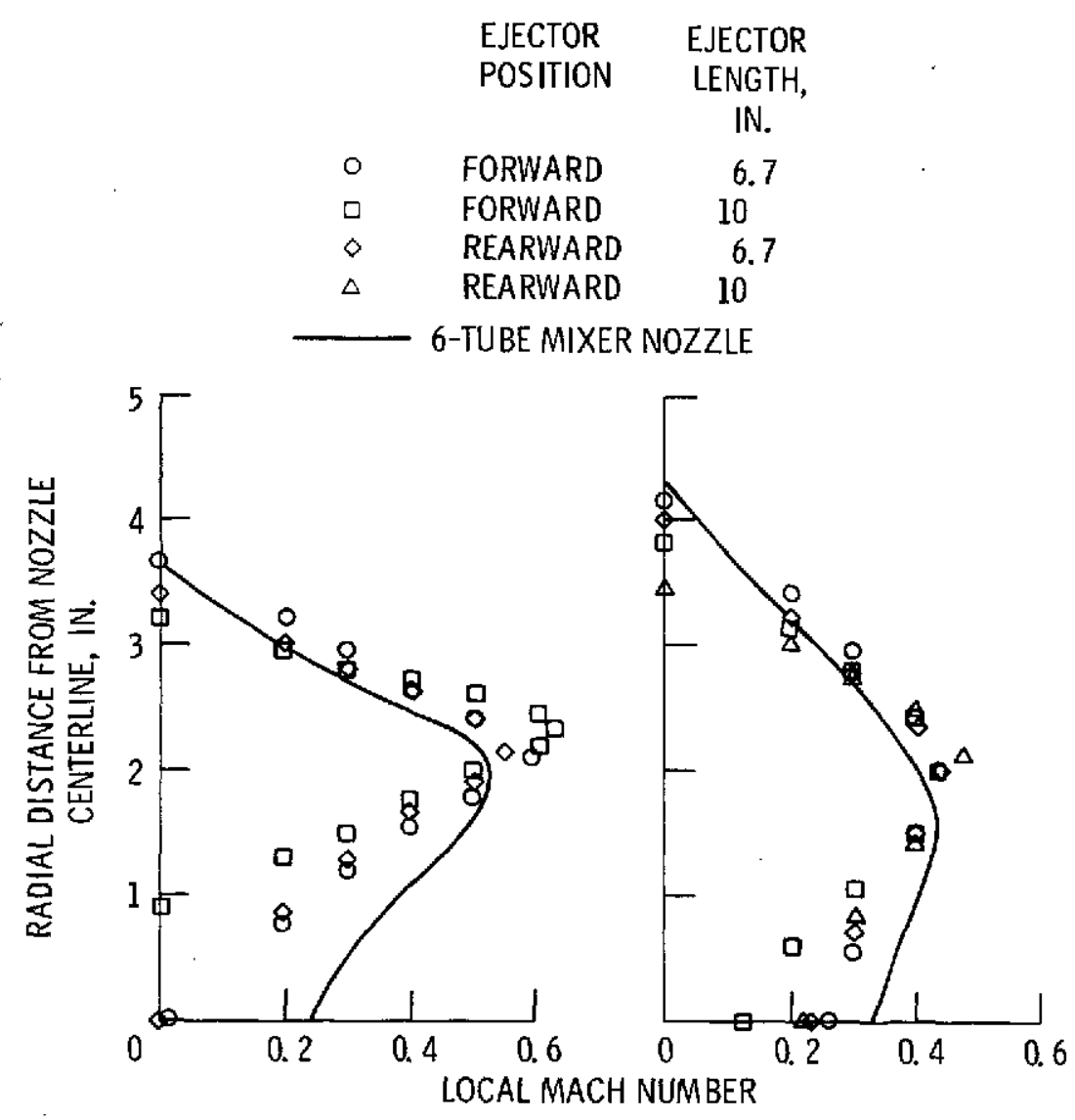

(a) $X / D_{T}, 5.0$.

(b) $X / D_{\mathrm{T}}, 7.0$.

Figure 9. - Comparison of radial profiles of velocity for ejector configurations with baseline mixer nozzle profiles. Zero forward velocity; $M_{0}, 0.98$. 
FORWARD POSITION

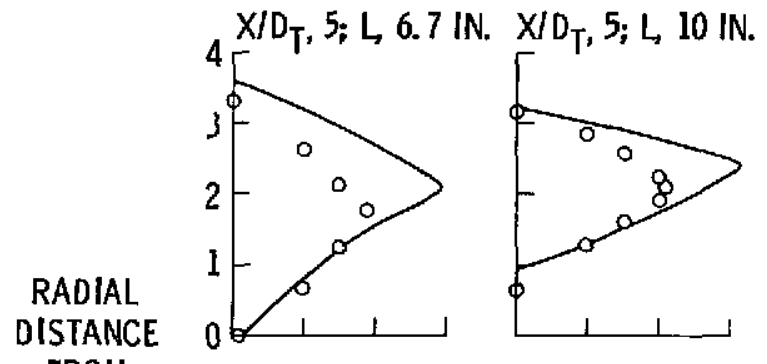

REARWARD

POSITION

$X / D_{T}, 5 ; L, 6.7 \mathrm{IN}$.

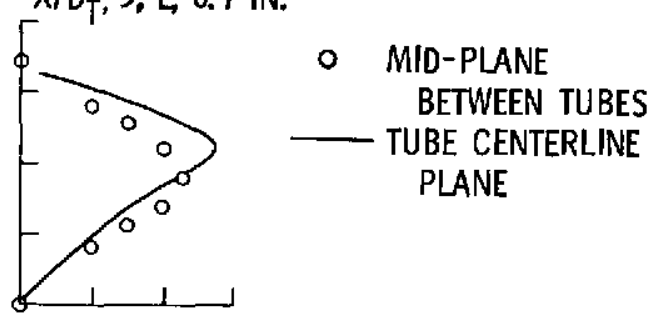

FROM

NOZZLE CENTERLINE,

IN.

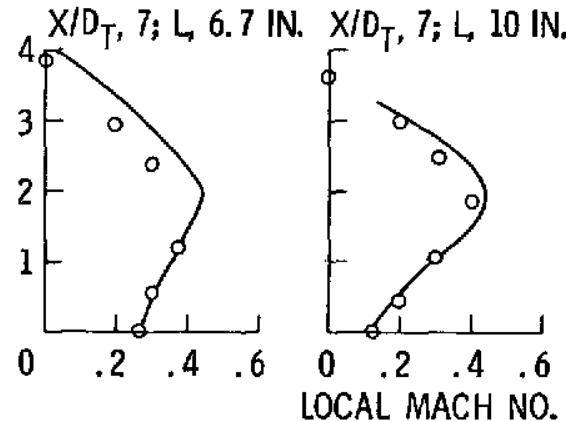

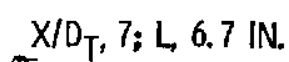

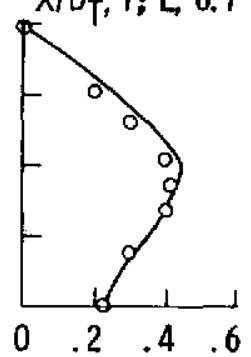

CS-70611

Figure 10. - Comparison of radial profiles of velocity in tube centerline plane with profiles in mid-plane between tubes. $M_{0}, 0.98$; zero forward velocity. 

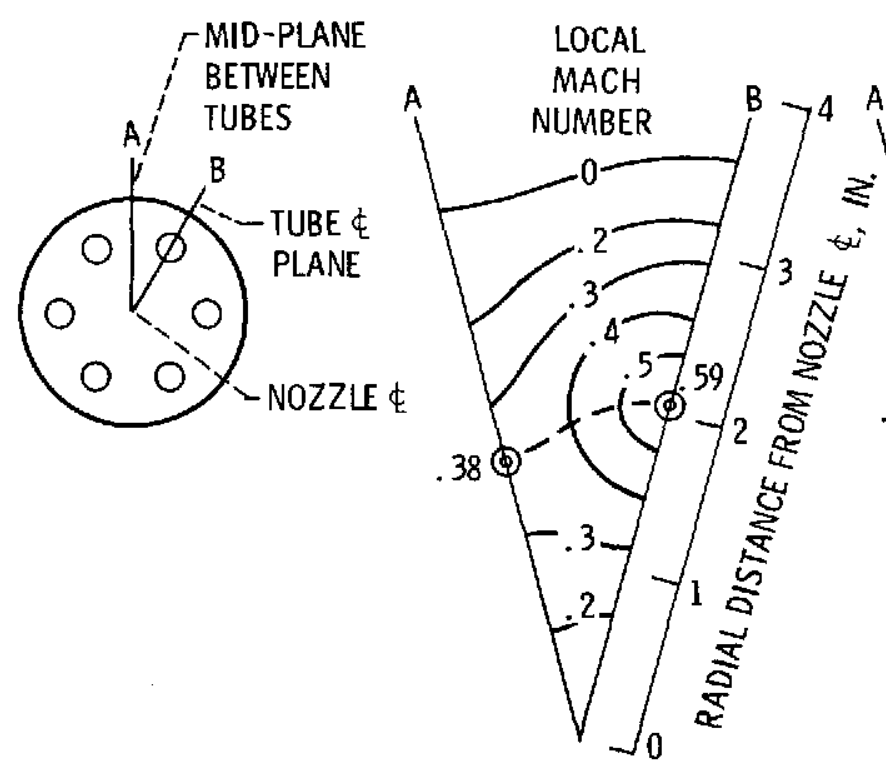

PEAK LOCAL AXIAL VELOCITY

(a) $X / D_{T}, 5$; L, $6.7 \mathrm{IN}$;

FORWARD EJECTOR

POSITION. (b) $X / D$ T $5 ; L, 10 I N$; FORWARD EJECTOR POSITION.

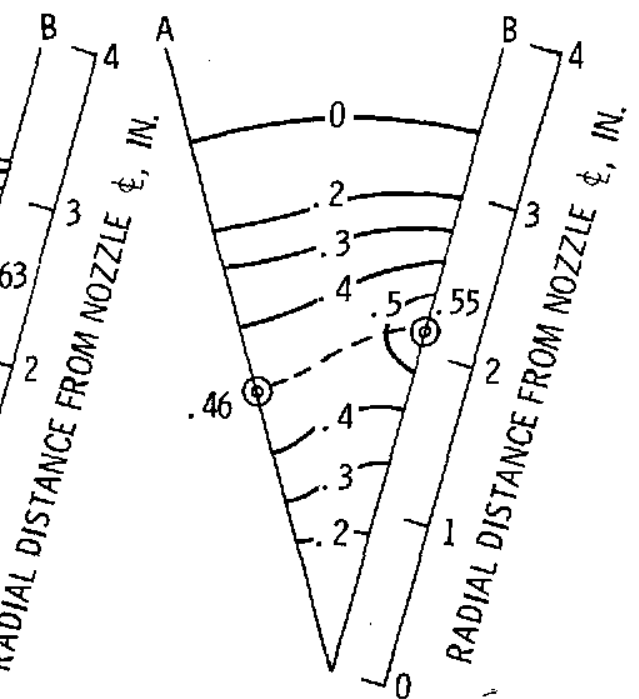

(c) $X / D_{T}, 5 ; L, 6.7 \mathrm{IN}$.

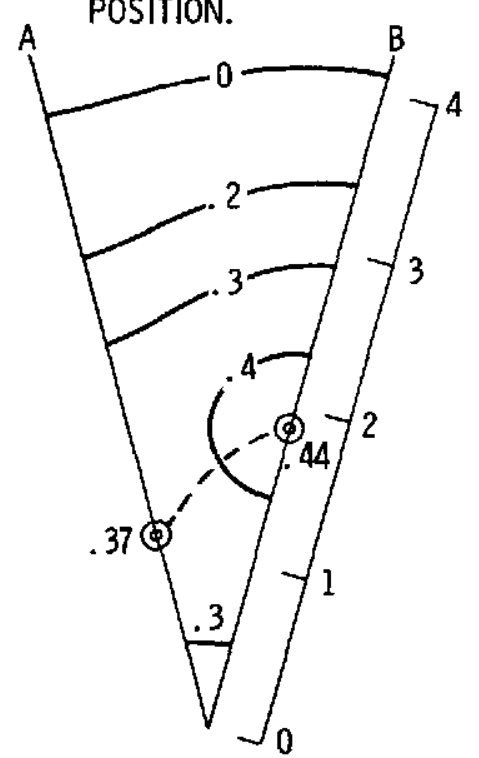

(d) $X / D$, 7; L, $6.7 \mathrm{IN}$; FORWARD EJECTOR POSITION.

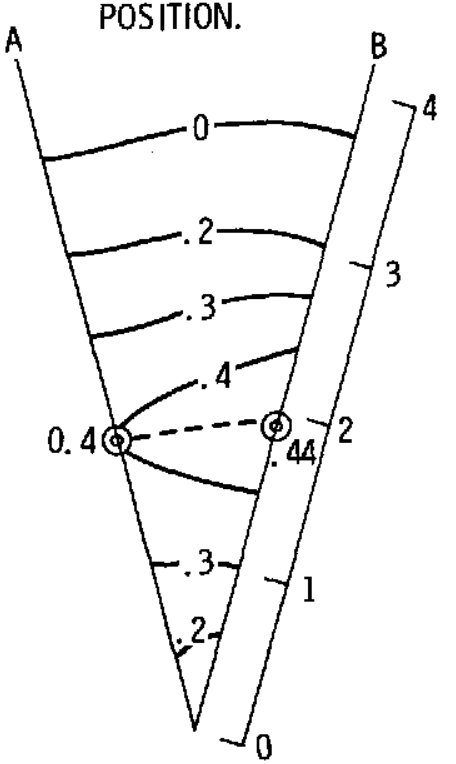

(e) X/D , 7; L, $10 \mathrm{IN}$; FORWARD EJECTOR POSITION.
REARWARD EJECTOR POSITION.

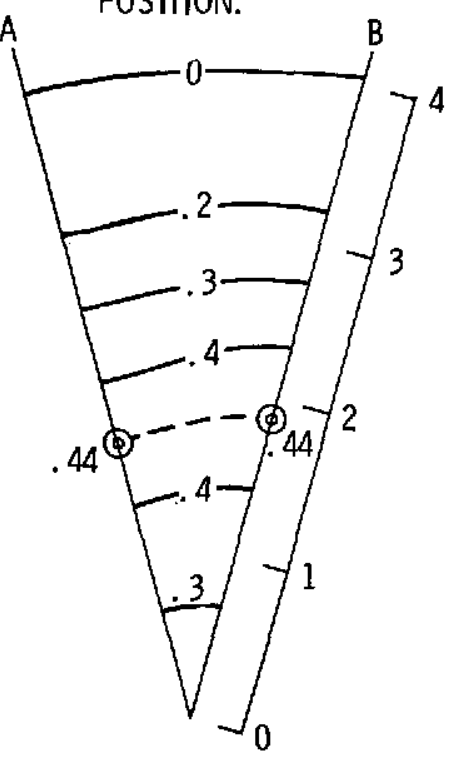

(f) $X / D_{T}, 7 ; L, 6.7 \mathrm{IN}$.; REARWARD EJECTOR POSITION.

Figure 11. - Circumferential sector velocity profiles for typical ejector configurations. $M_{j}, 0.98$; zero forward velocity. 

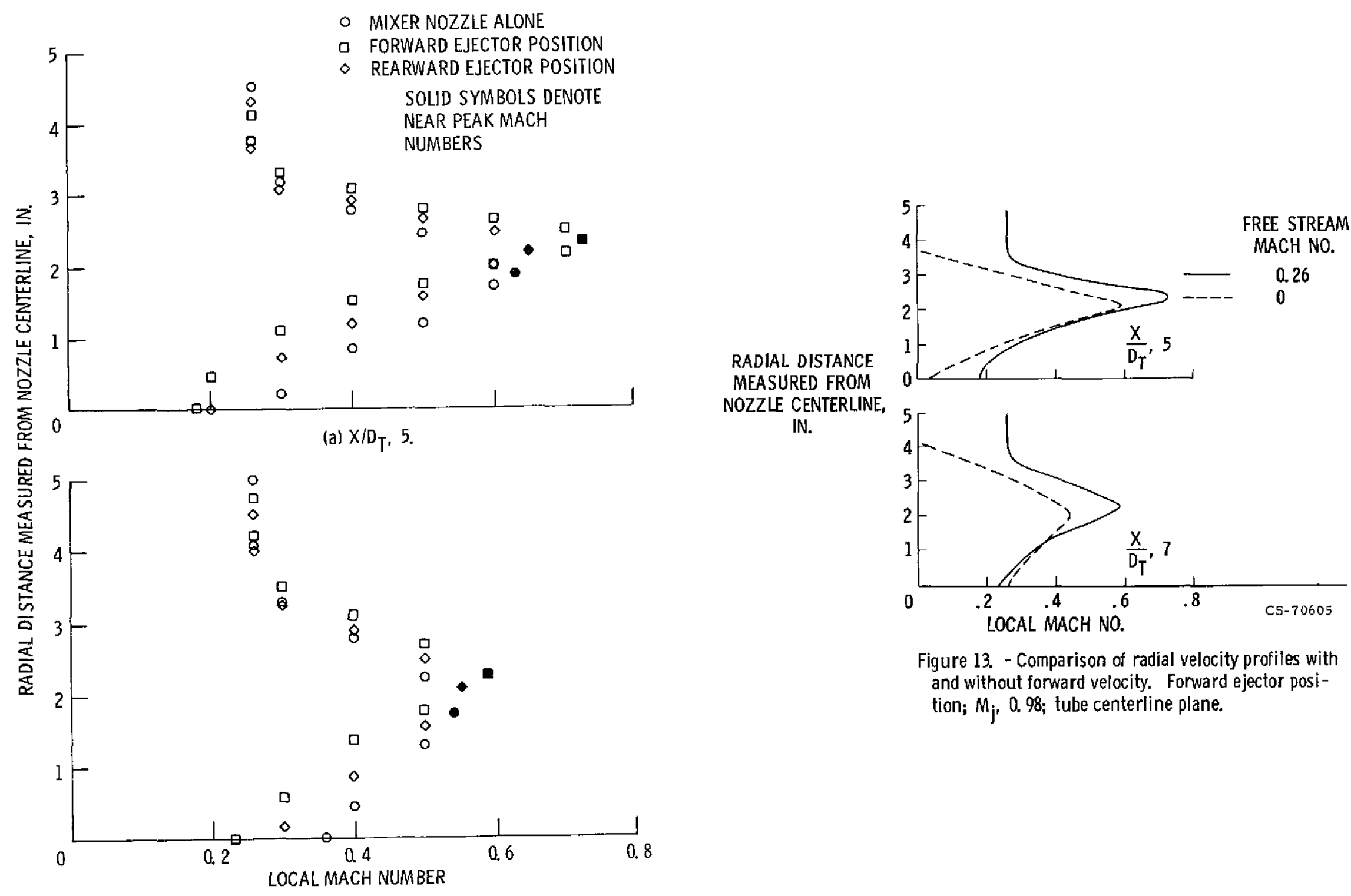

(b) $X / D_{T}, 7$.

Figure 12 - Typical radial velocity profiles with forward velocity. $M_{j}, 0.98 ; M_{0}, 0.26$. Tube centerline plane. 
(1) DEPARTURE POINT OF COALESCING CORE FROM

SINGLE ELEMENT CURVE

(2) START OF FULLY COALESCED CORE DECAY

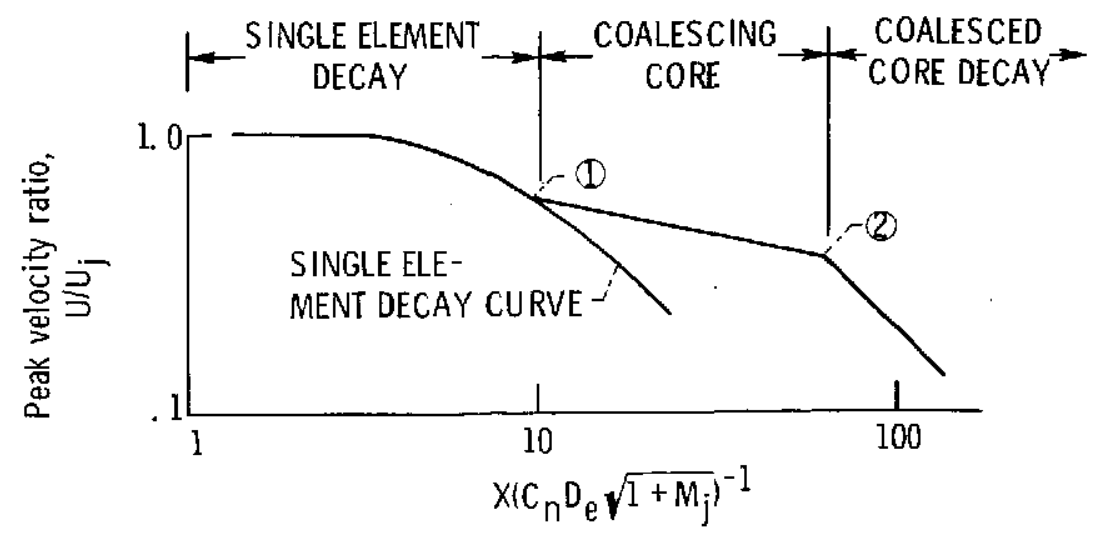

Figure 14. - Significant mixed-flow regimes for multi-element nozzles.

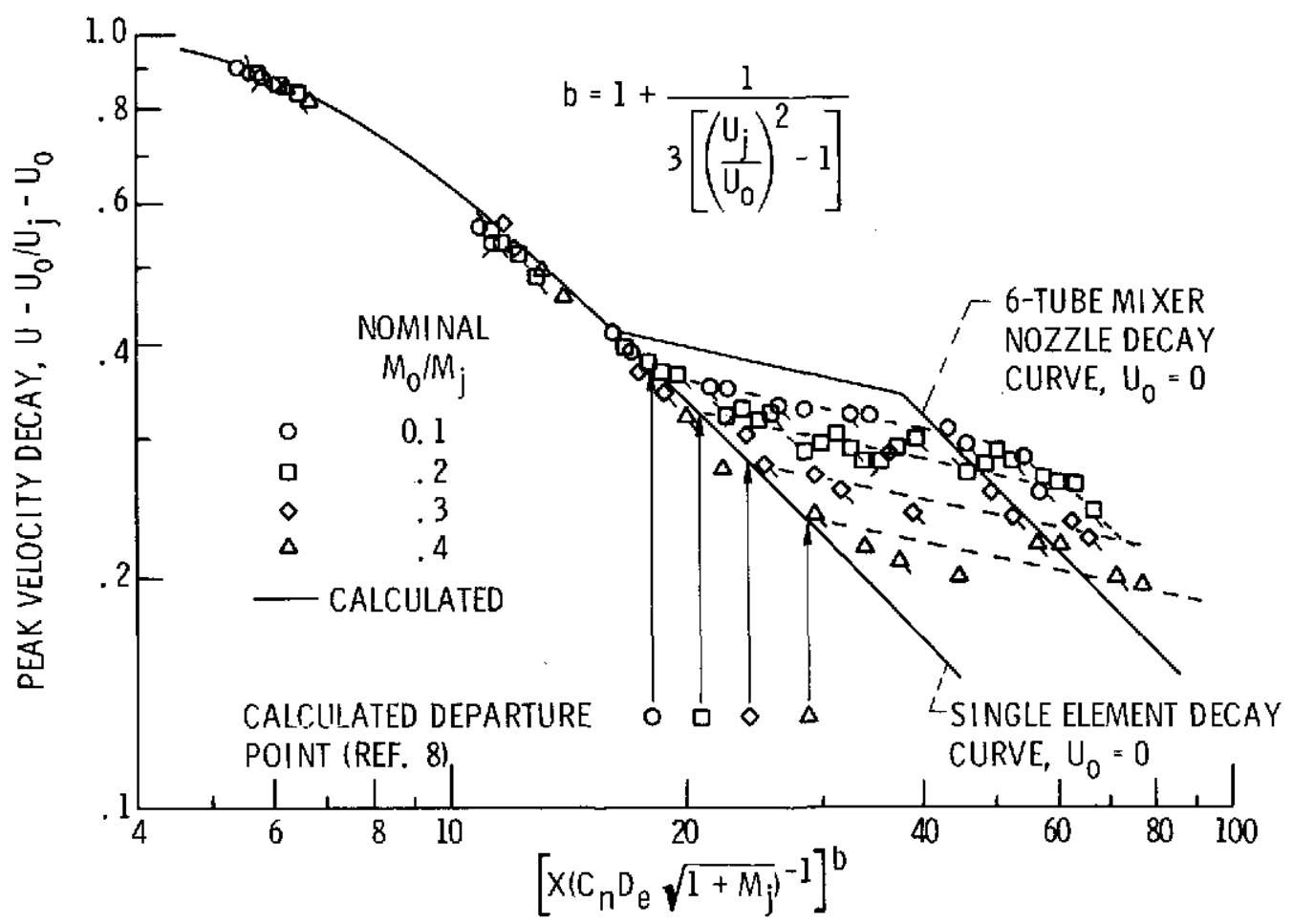

Figure 15. - Correlation of relative velocity decay for 6-tube mixer nozzle. Reference 9. 


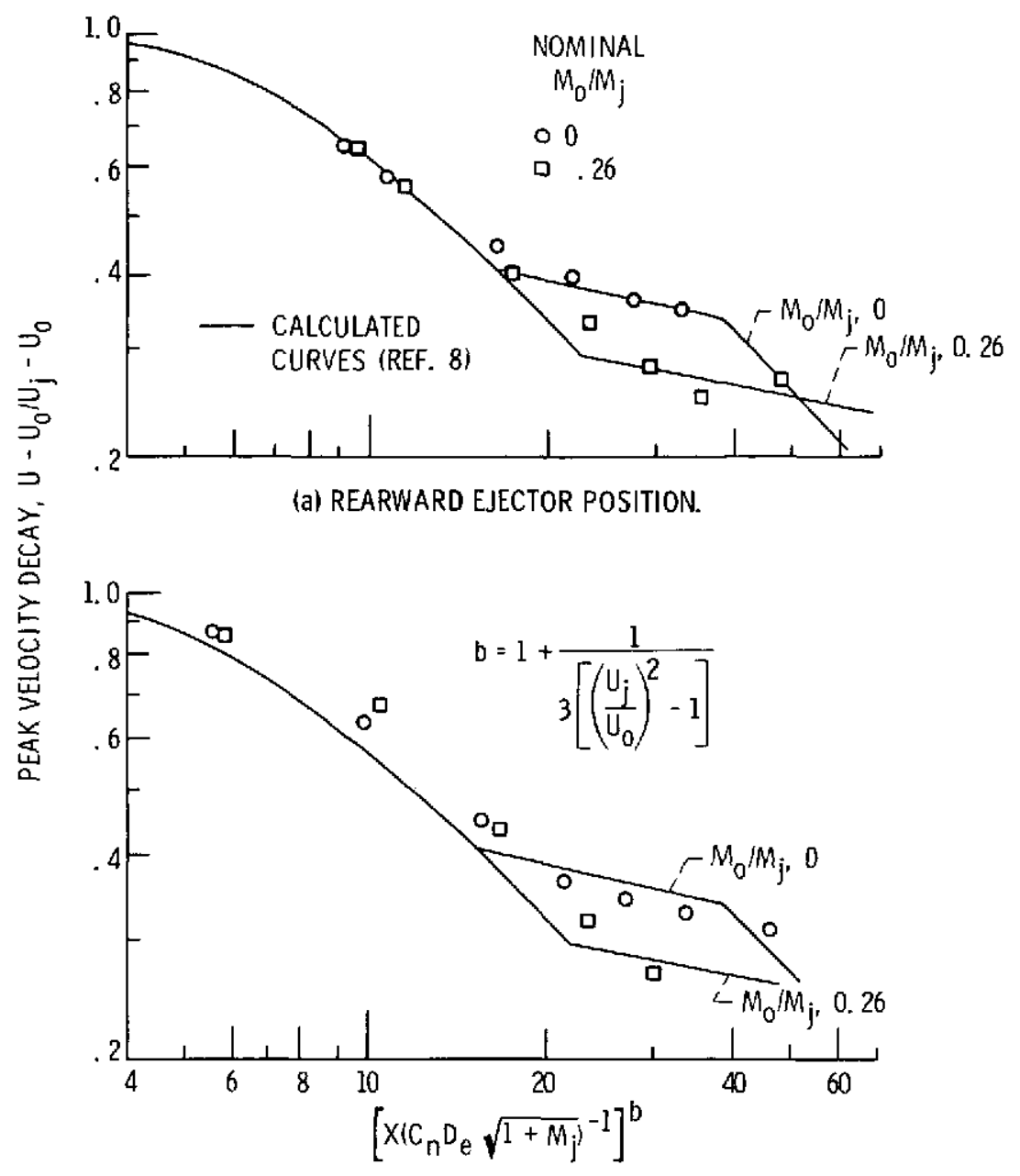

(b) FORWARD EJECTOR POSITION.

Figure 16. - Correlated peak relative velocity decay for 6-tube mixer nozzle with ejector. Jet Mach number, 0.98; reference 9 . 


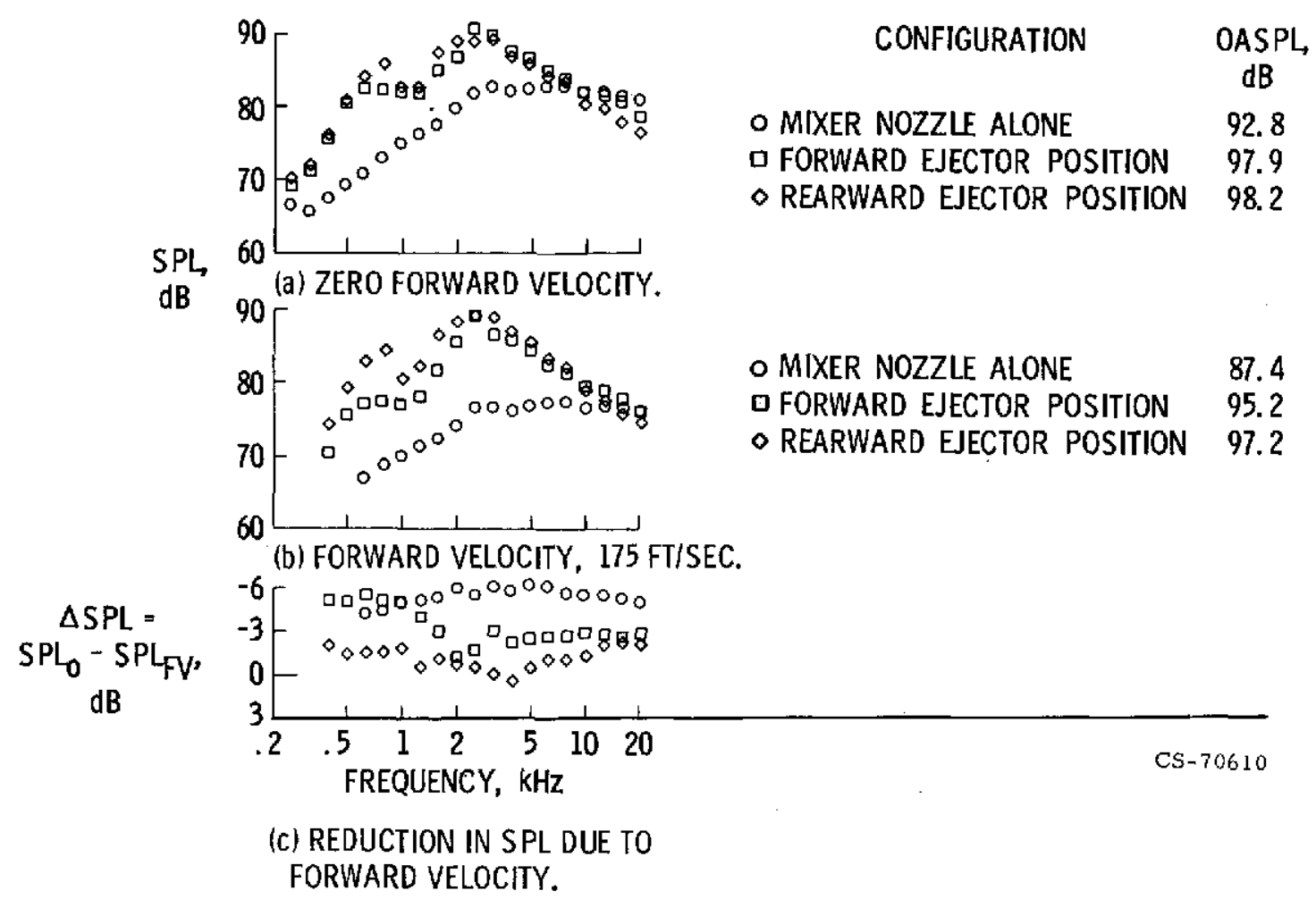

Figure 17. - Comparison of nozzle and ejector configuration spectra. Nominal jet velocity, $840 \mathrm{ft} / \mathrm{sec}$; directivity angle, $90^{\circ}$.

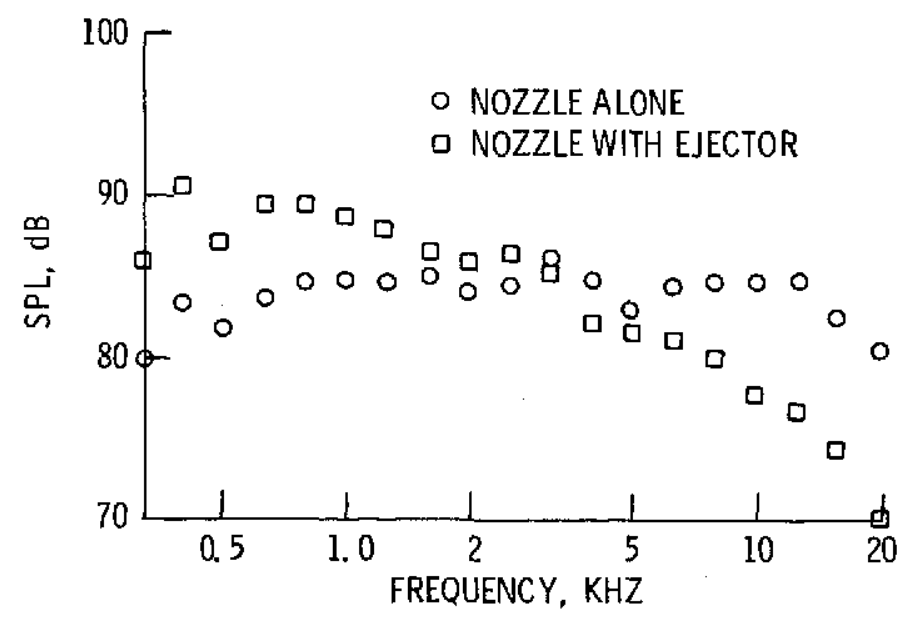

Figure 18. - Large scale 8-lobed mixer nozzle spectra with and without ejector. Nozzle pressure ratio, 1. 3; directivity angle, $85^{\circ}$; microphone radius, $50 \mathrm{ft}$. 


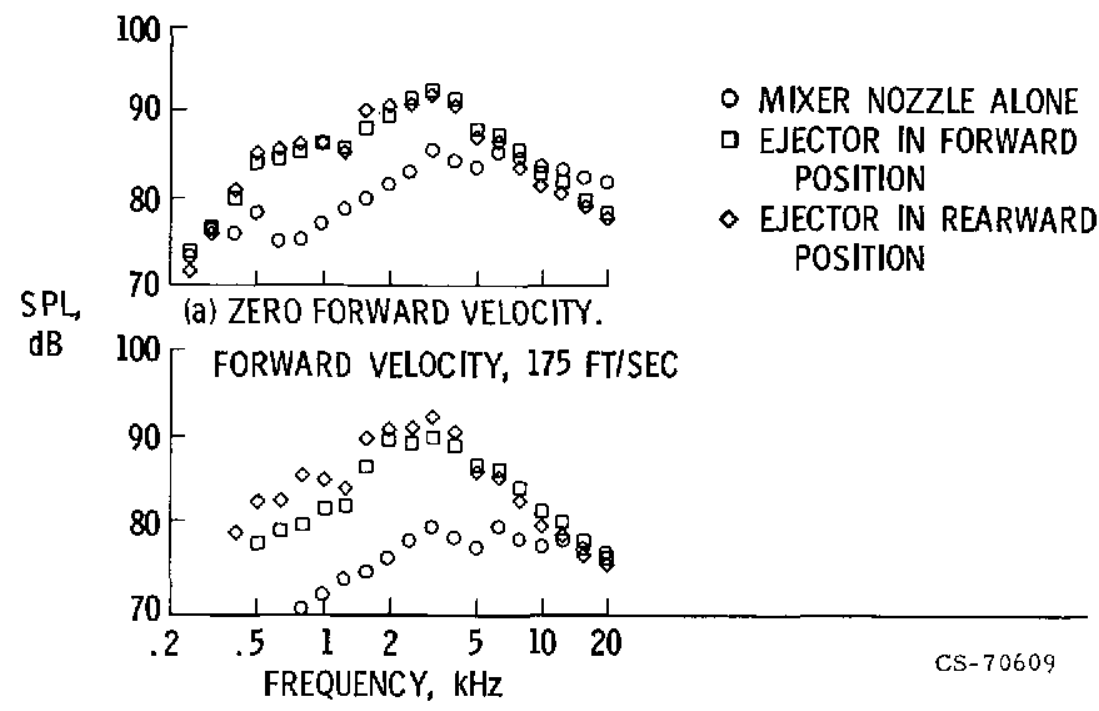

(b) FORWARD VELOCITY, $175 \mathrm{FT} / \mathrm{SEC}$.

Figure 19. - Spectra comparisons of mixer nozzle with wing and ejector configurations with wing. Directivity angle, $90^{\circ}$; jet velocity, $840 \mathrm{ft} / \mathrm{sec}$.

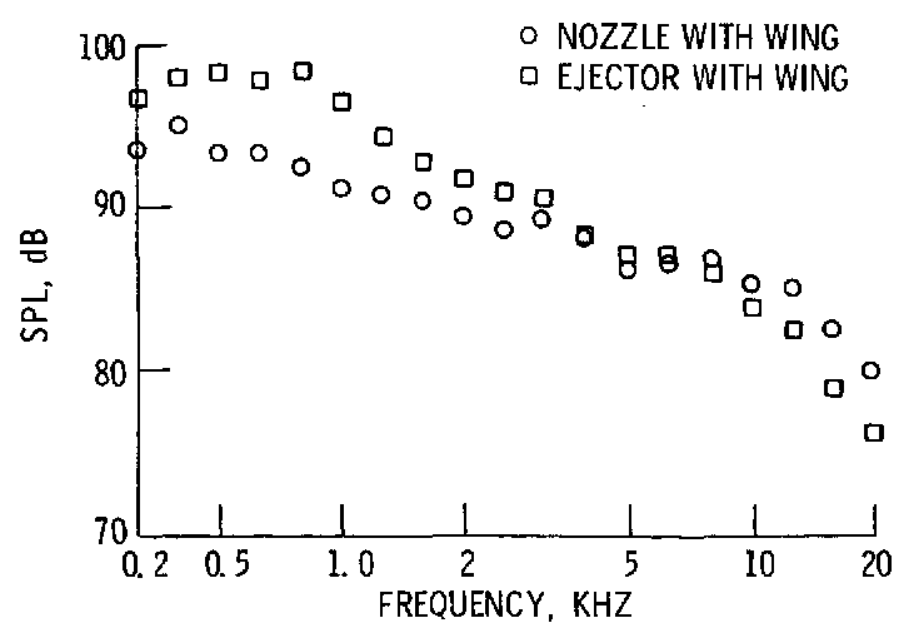

Figure 20. - Spectra for large-scale 8-lobed mixer nozzle with and without ejector and with wing. Nozzle pressure ratio, 1. 3; directivity angle, $90^{\circ}$; microphone angle, $85^{\circ}$; flaps deflected, $60^{\circ}$. 
SPL

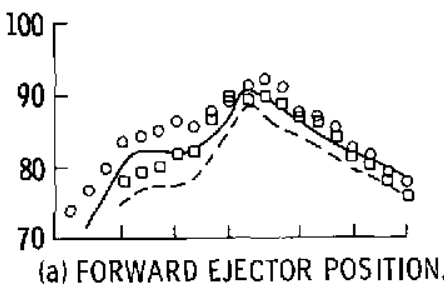

$\mathrm{dB}$

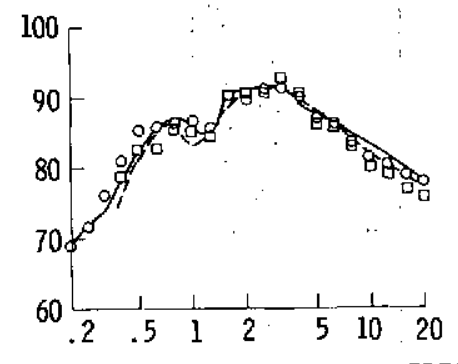

PREQUE

(b) REARWARD EJECTOR POSITION.

Figure 21. - Comparison of spectra for all nozzle configurations with and without wing. Directivity angle; $90^{\circ}$; jet velocity, $840 \mathrm{ft} / \mathrm{sec}$.

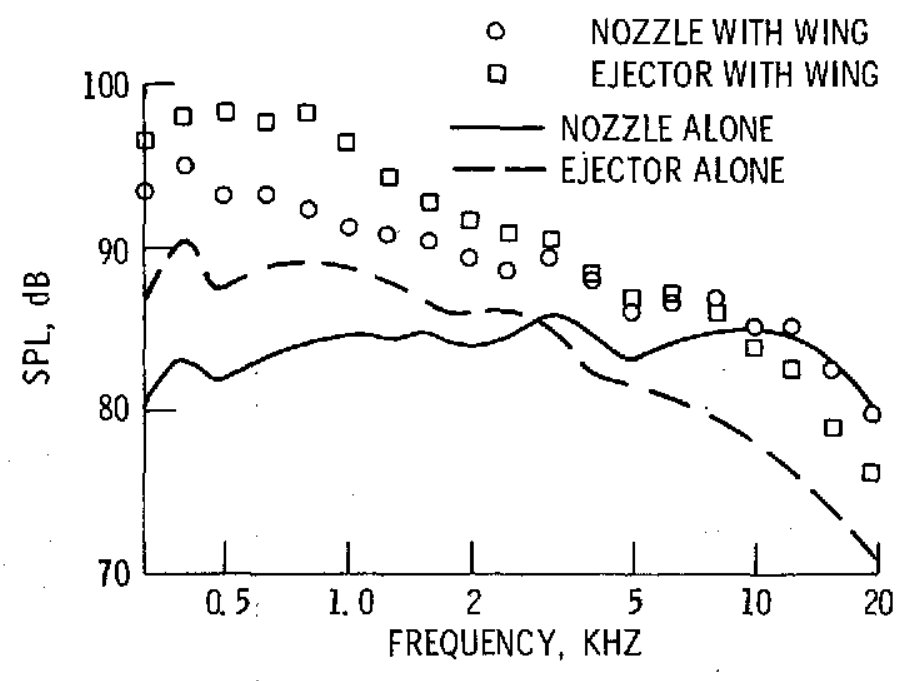

Figure 22 - Comparison of large-scale 8-Iobed mixer nozzle spectra with and without a wing. Directivity angle, $85^{\circ}$; jet velocity, $840 \mathrm{ft} / \mathrm{sec}$; flaps deflected $60^{\circ}$; microphone radius, $50 \mathrm{ft}$.

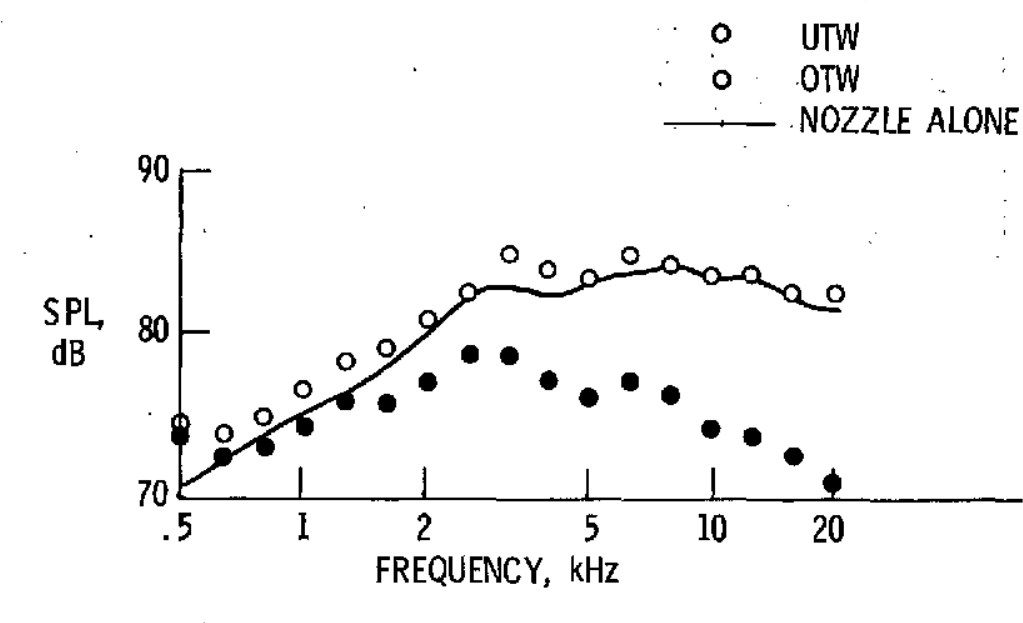

Figure 23. - Comparison of spectra for UTW and OTW orientation with baseline 6-tube mixer nozzle and wing. Directivity angle, $90^{\circ}$; jet velocity, $946 \mathrm{ft} / \mathrm{sec}$; forward velocity, $175 \mathrm{ft} / \mathrm{sec}$. 


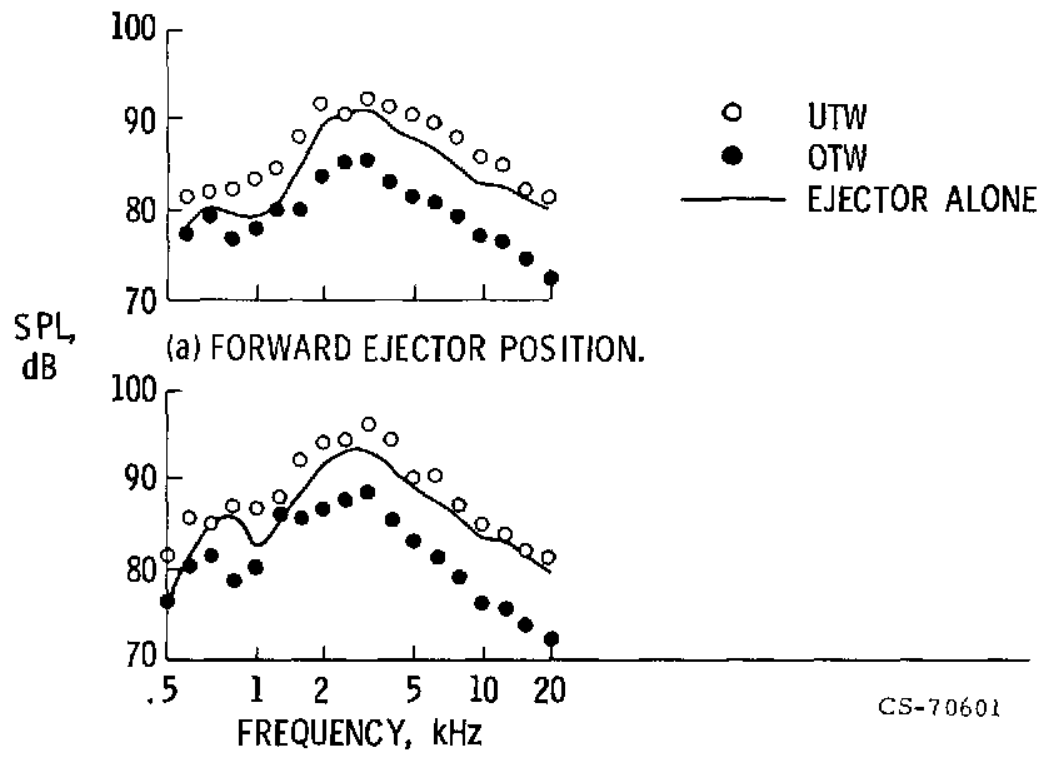

(b) REARWARD EJECTOR POSITION.

Figure 24. - Comparison of spectra for UTW and OTW orientation with ejector configurations and wing. Directivity angle, $90^{\circ}$; jet velocity, $940 \mathrm{ft} / \mathrm{sec}$; forward velocity, $175 \mathrm{ft} / \mathrm{sec}$.

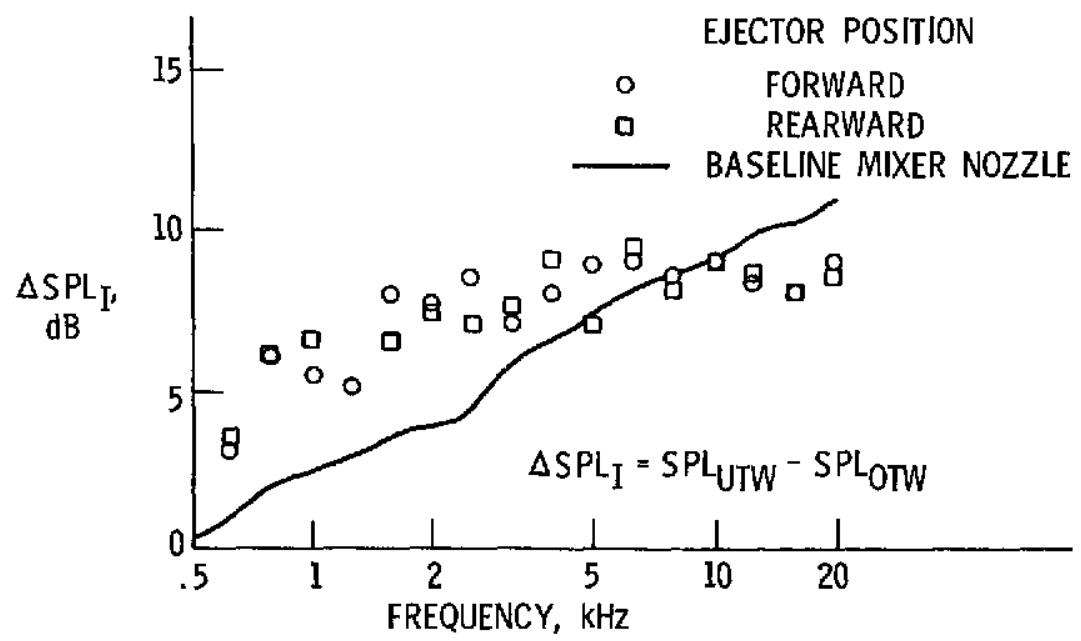

Figure 25. - Comparison of SPL difference between UTW and OTW orientation of baseline nozzle and ejector, all with wing. Directivity angle, $90^{\circ}$; jet velocity, $940 \mathrm{ft} / \mathrm{sec}$; forward velocity, $175 \mathrm{ft} / \mathrm{sec}$. 

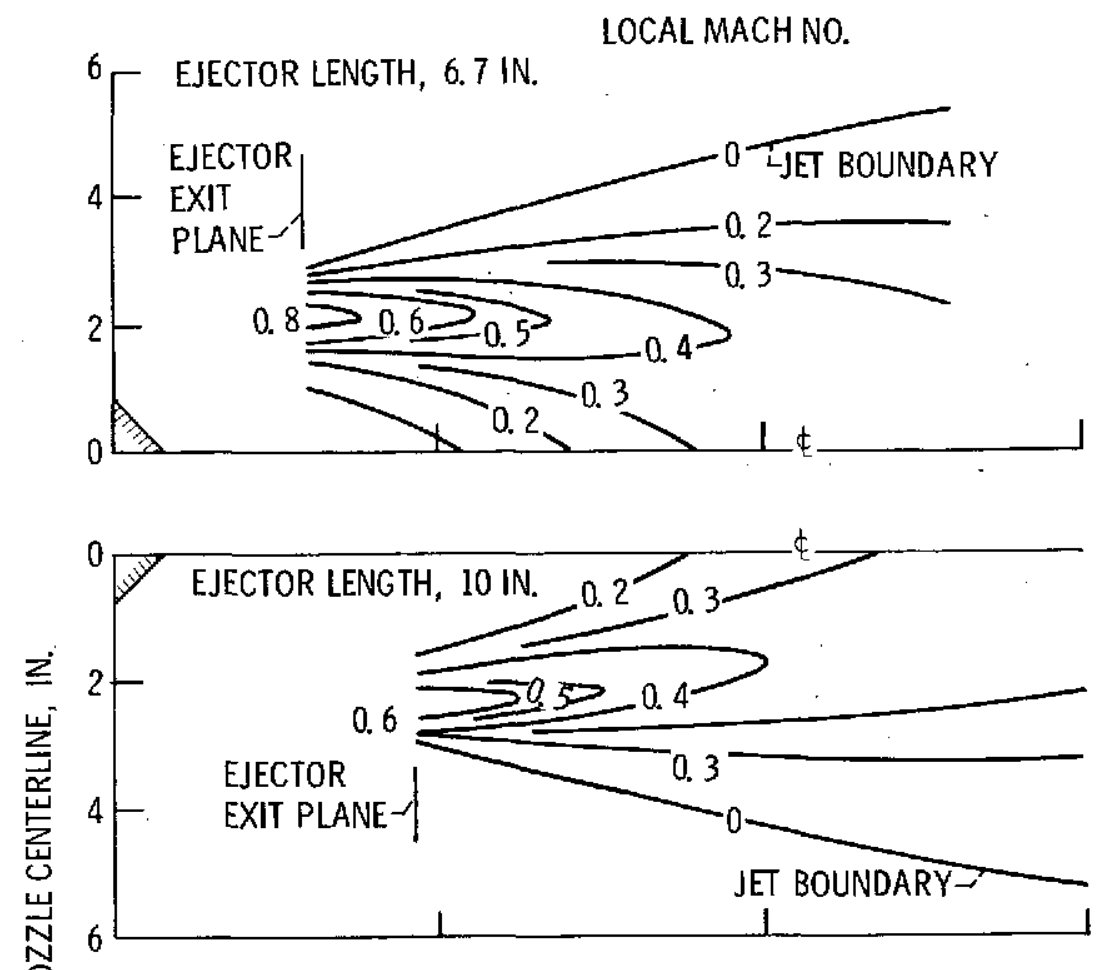

(a) FORWARD EJECTOR POSITION.
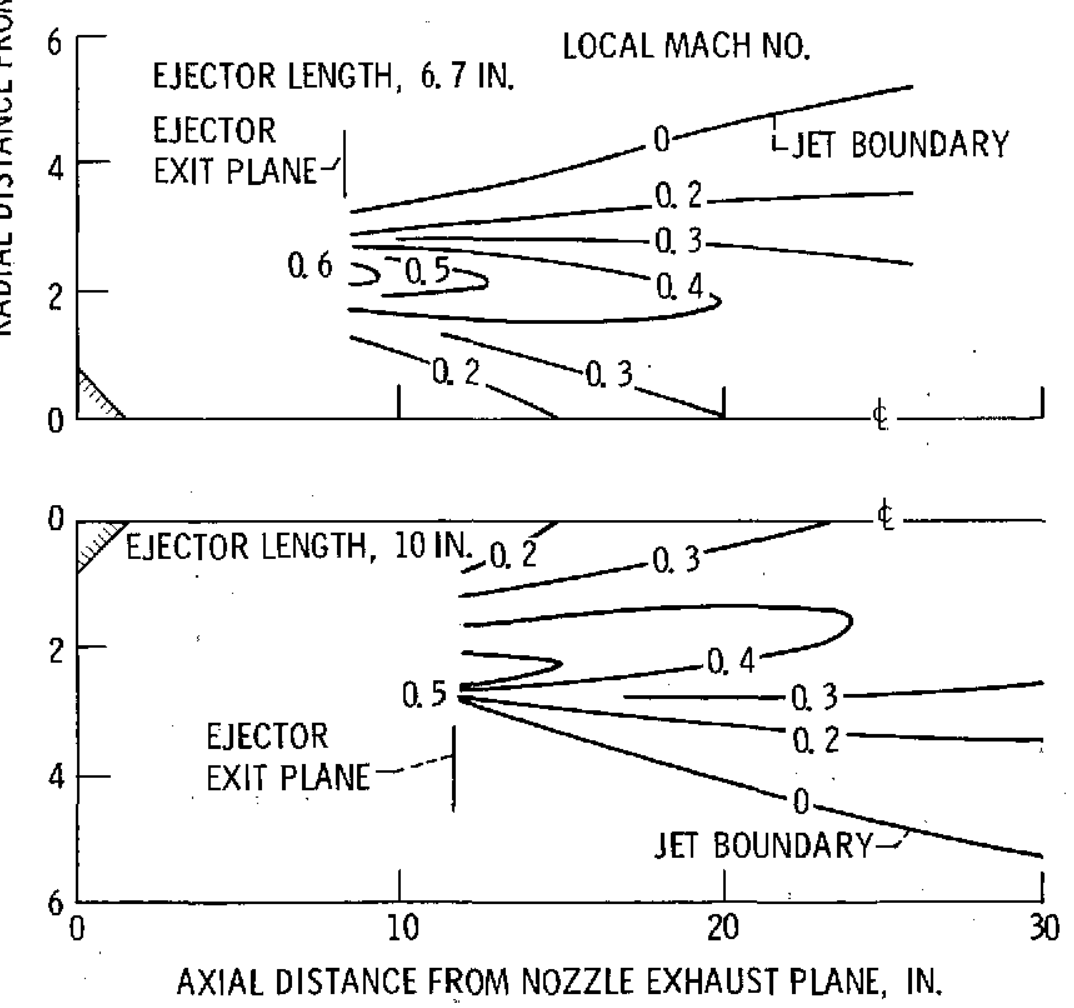

(b) REARWARD EJECTOR POSITION.

Figure 26. - Effect of ejector length on flow field. Ejector I. D. , 5.5 in.; zero forward velocity; $M_{j}$, 0.98 ; tube centerline plane. 


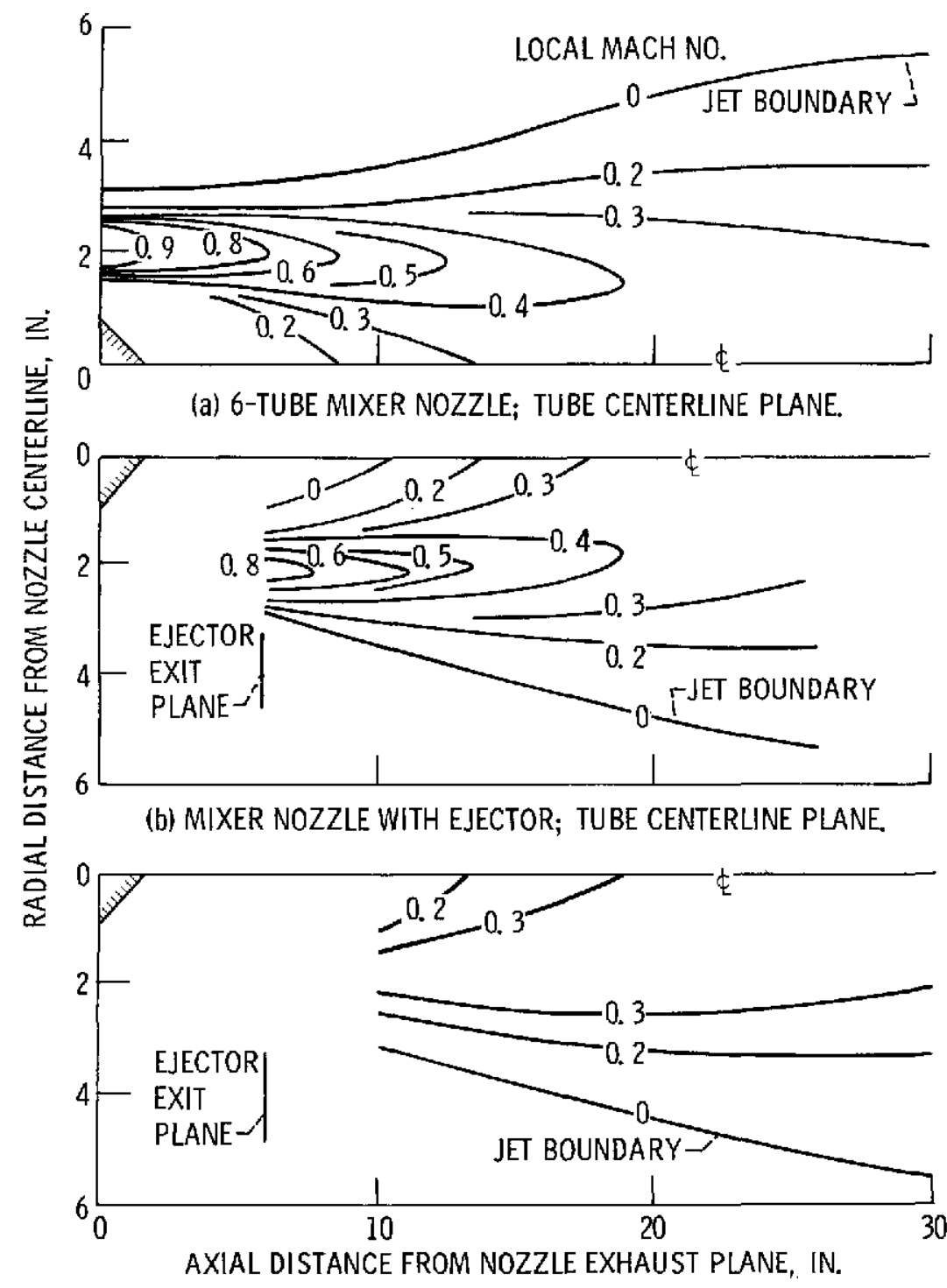

(c) MIXER NOZZLE WITH EJECTOR; MID-PLANE BETWEEN TUBES.

Figure 27. - Comparison of 6-tube mixer nozzle flow field with and without ejector. Fonward ejector position; $M_{0}, 0$; $M_{j}, 0.98 ; L, 6.7$ in.

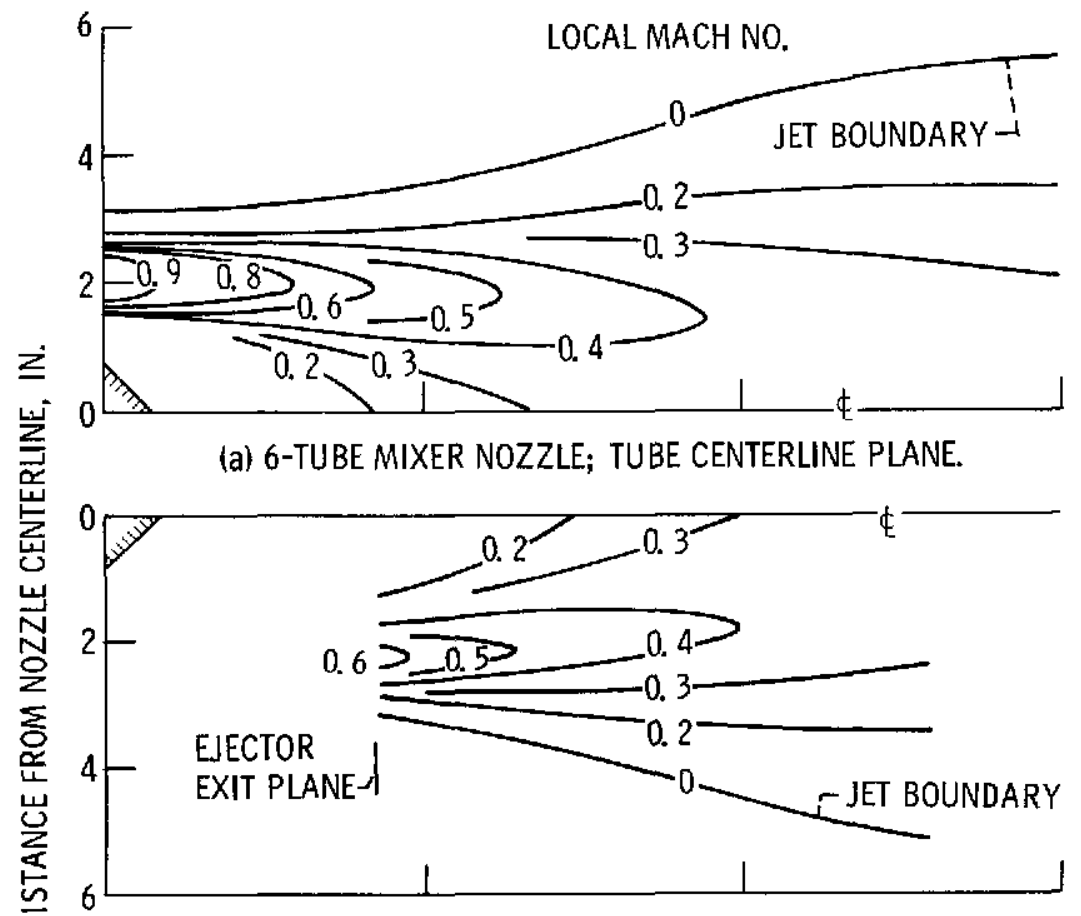

(b) MIXER NOZZLE WITH EJECTOR; TUBE CENTERLINE PLANE.

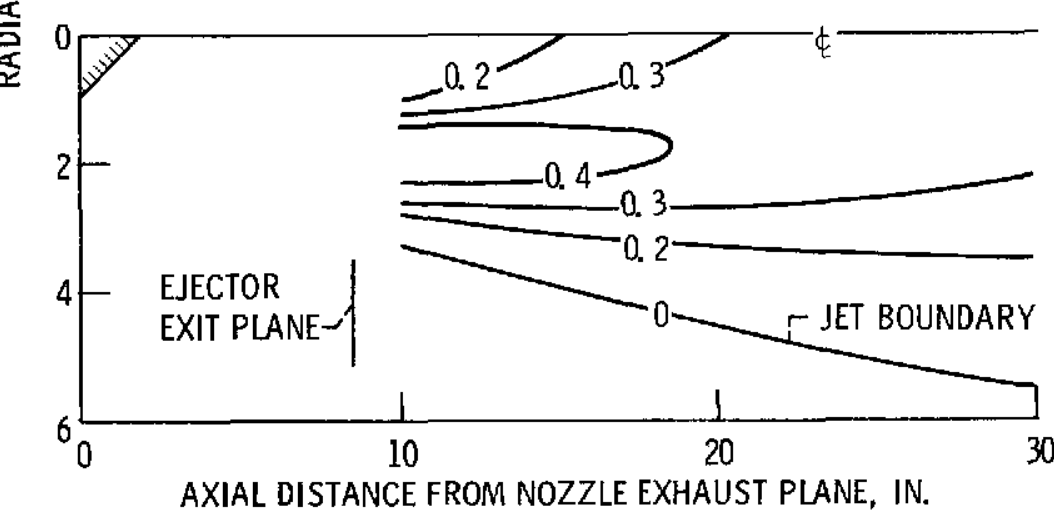

(c) MIXER NOZZLE WITH EJECTOR; MID-PLANE BETWEEN TUBES.

Figure 28. - Comparison of 6-tube mixer nozzle flow field with and without ejector. Rearward ejector position; $M_{0}, 0 ; M_{j}, 0.98$; $\mathrm{L}, 6.7 \mathrm{in}$. 


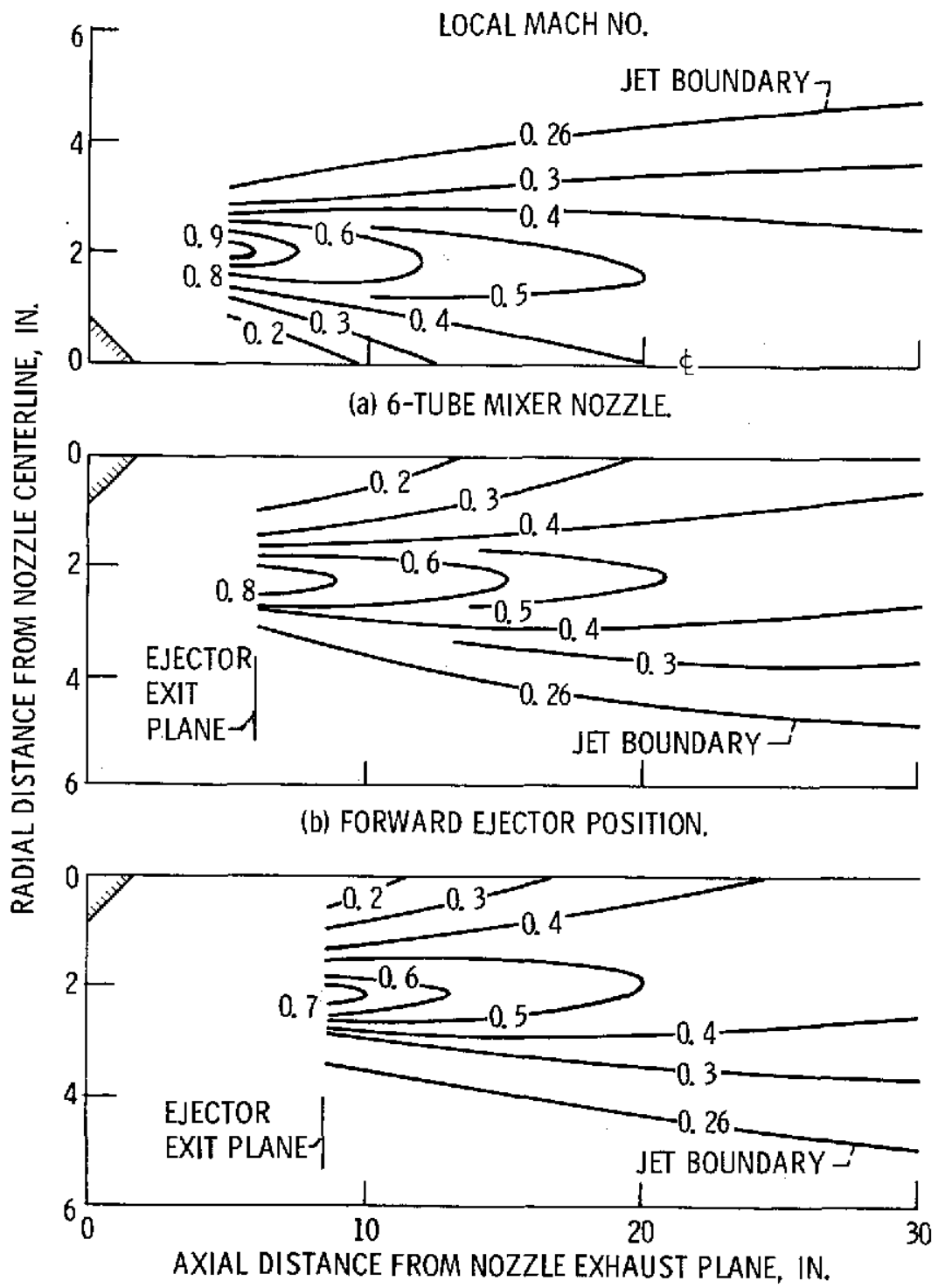

(c) REARWARD EJECTOR POSITION.

Figure 29. - Comparison of flow field for 6-tube mixer nozzle with and without ejector with forward velocity. $M_{j}, 0.98 ; M_{0}, 0.26$;
tube centerline plane. 

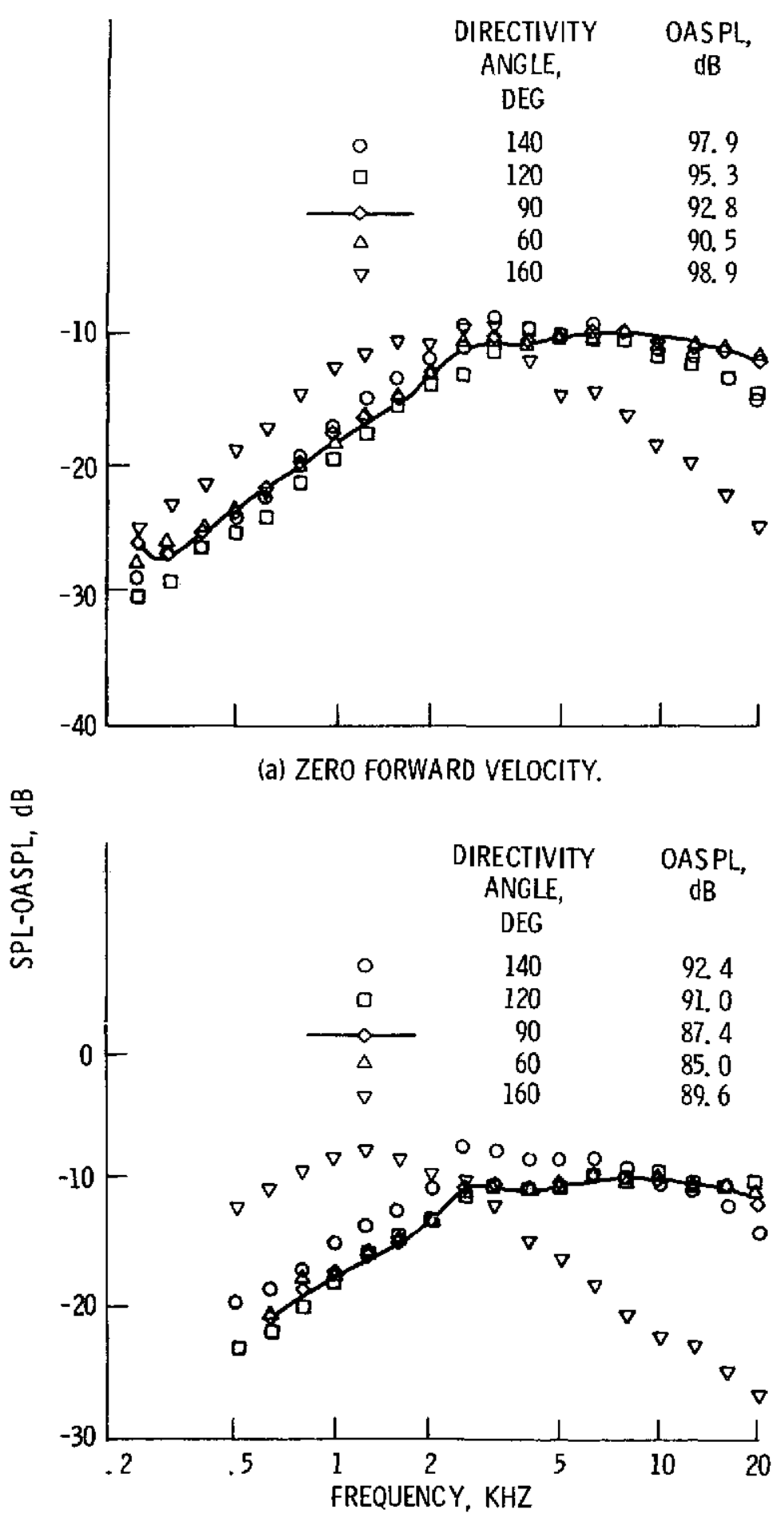

(b) FORWARD VELOCITY, $175 \mathrm{FT} / \mathrm{SEC}$.

Figure 30. - Spectral distribution for baseline 6-tube mixer nozzle. Jet velocity, $836 \mathrm{ft} / \mathrm{sec}$. 


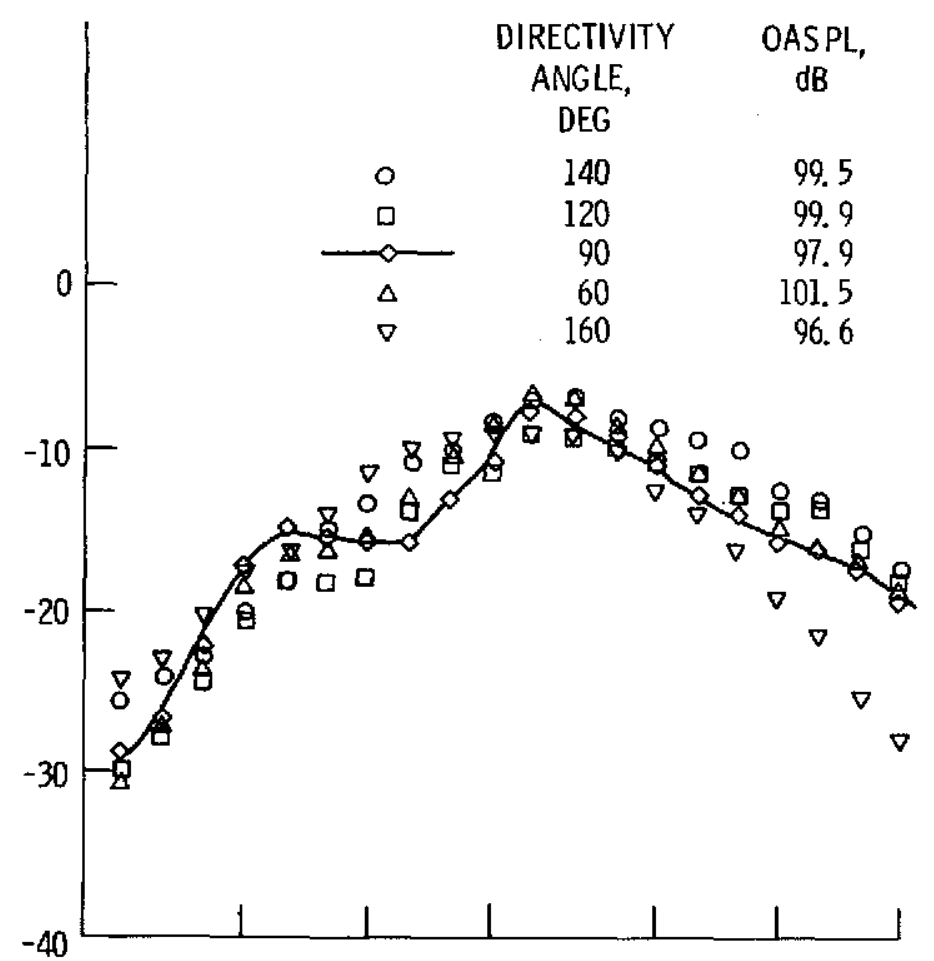

(a) ZERO FORWARD VELOCITY.

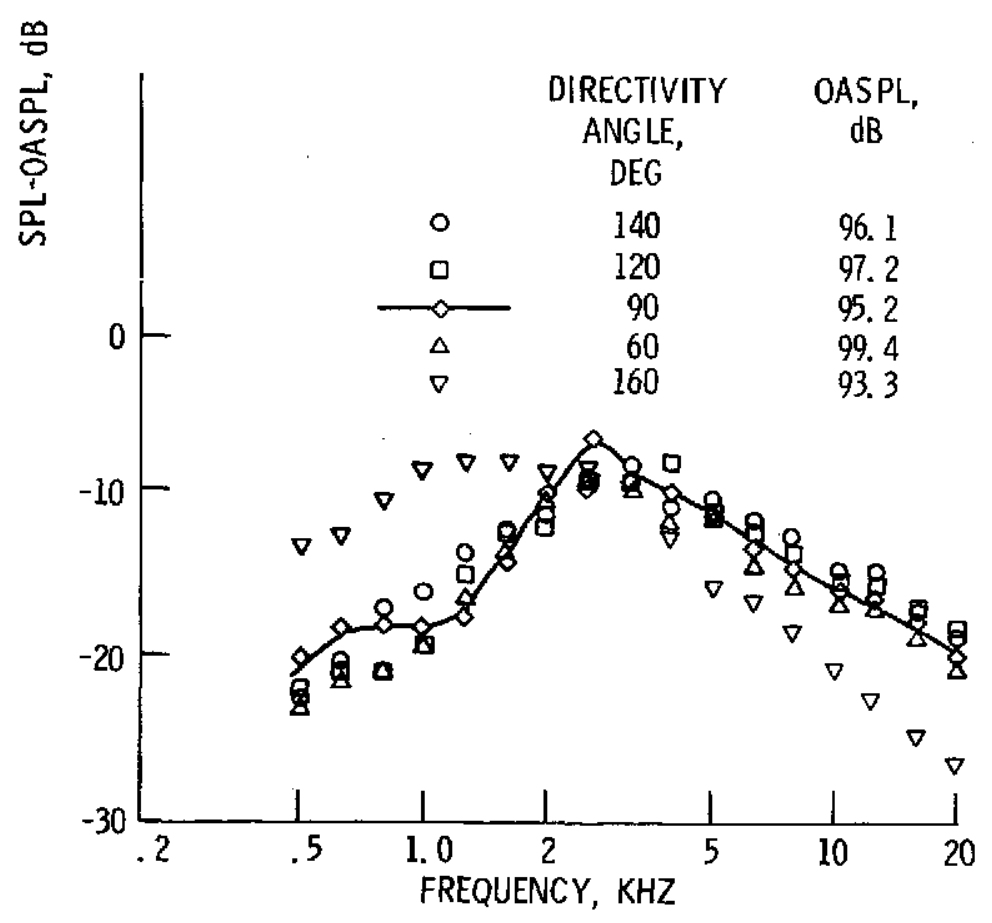

(b) FORWARD VELOCITY, 175 FT/SEC.

Figure 31. - Spectral distribution for 6-tube mixer nozzel with ejector in forward position. Jet velocity, $840 \mathrm{ft} / \mathrm{sec}$. 


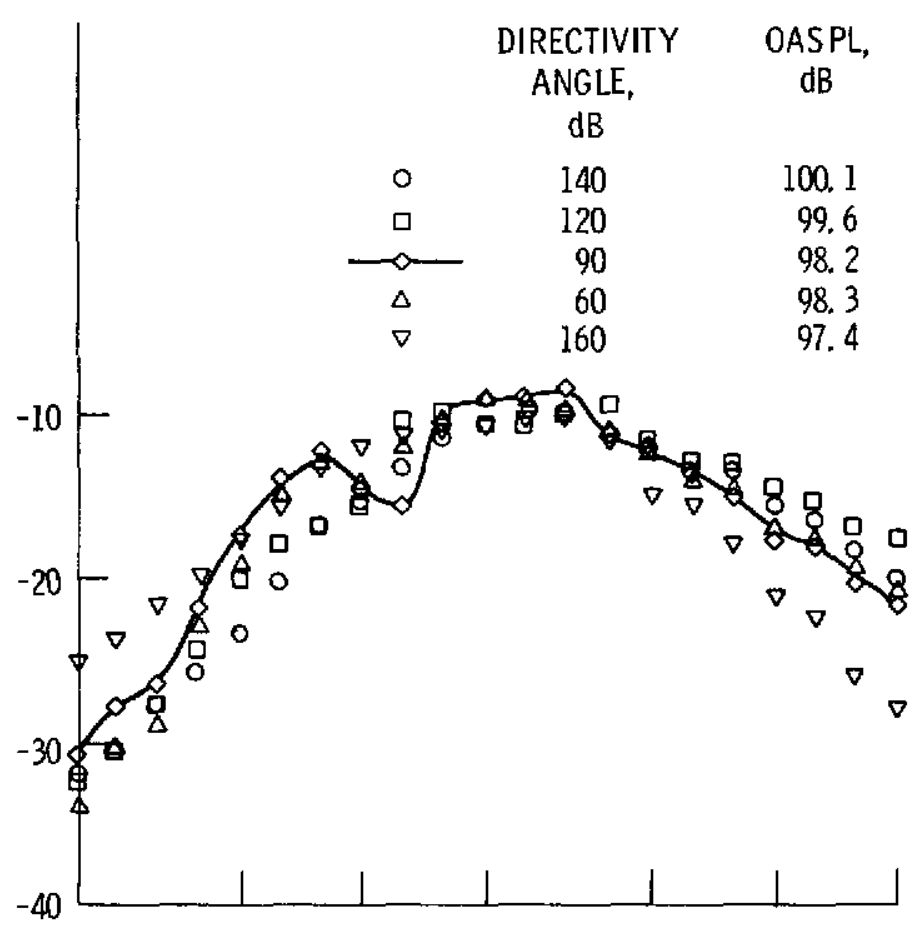

(a) ZERO FORWARD VELOCITY.

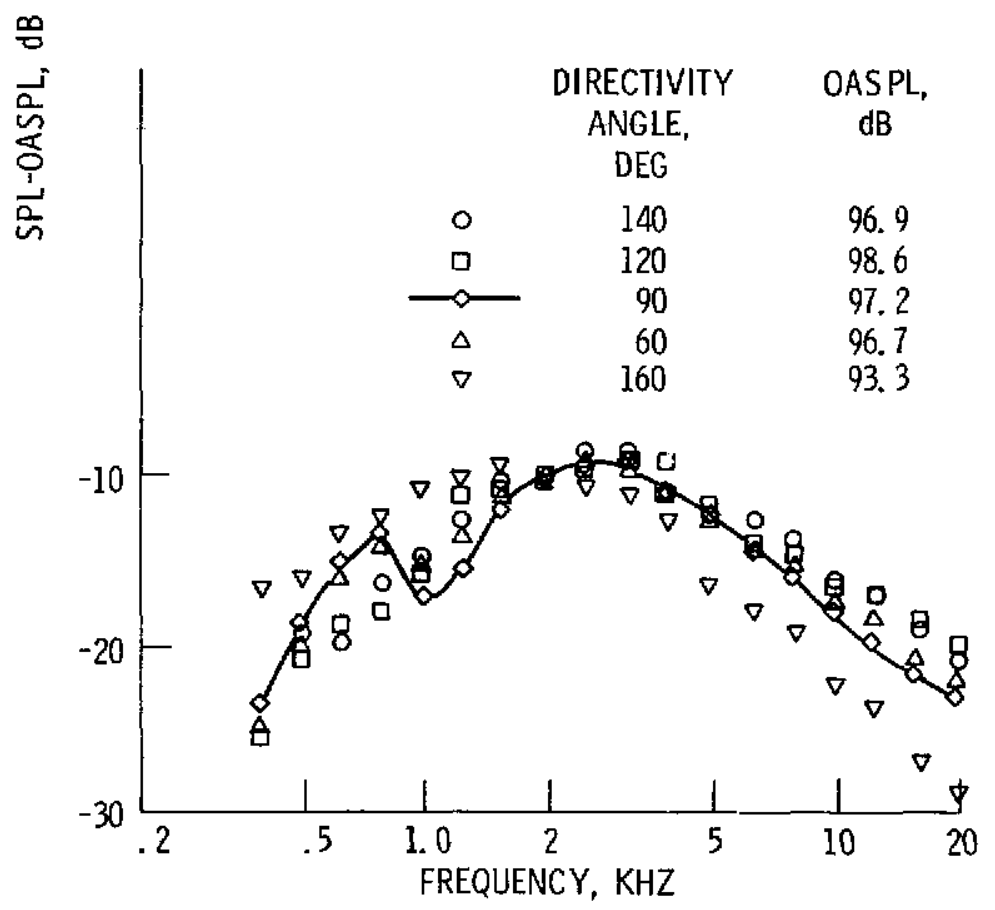

(b) FORWARD VELOCITY, 175 FT/SEC.

Figure 32. - Spectral distribution for 6-tube mixer nozzel with ejector in rearward position. Jet velocity, $840 \mathrm{ft} / \mathrm{sec}$. 


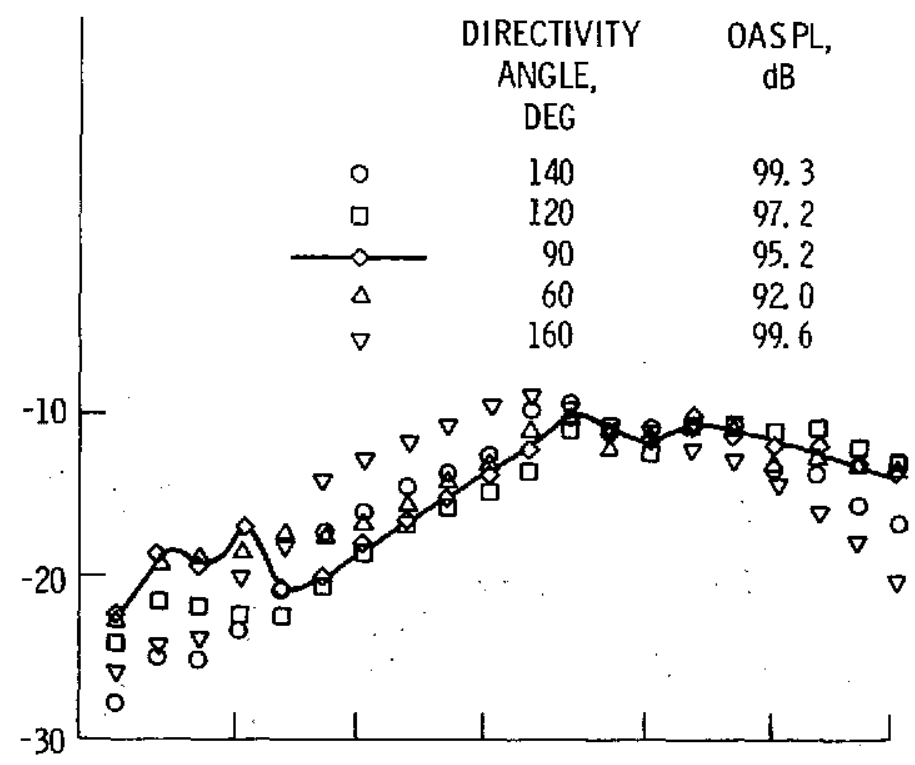

(a) ZERO FORWARD VELOCITY.

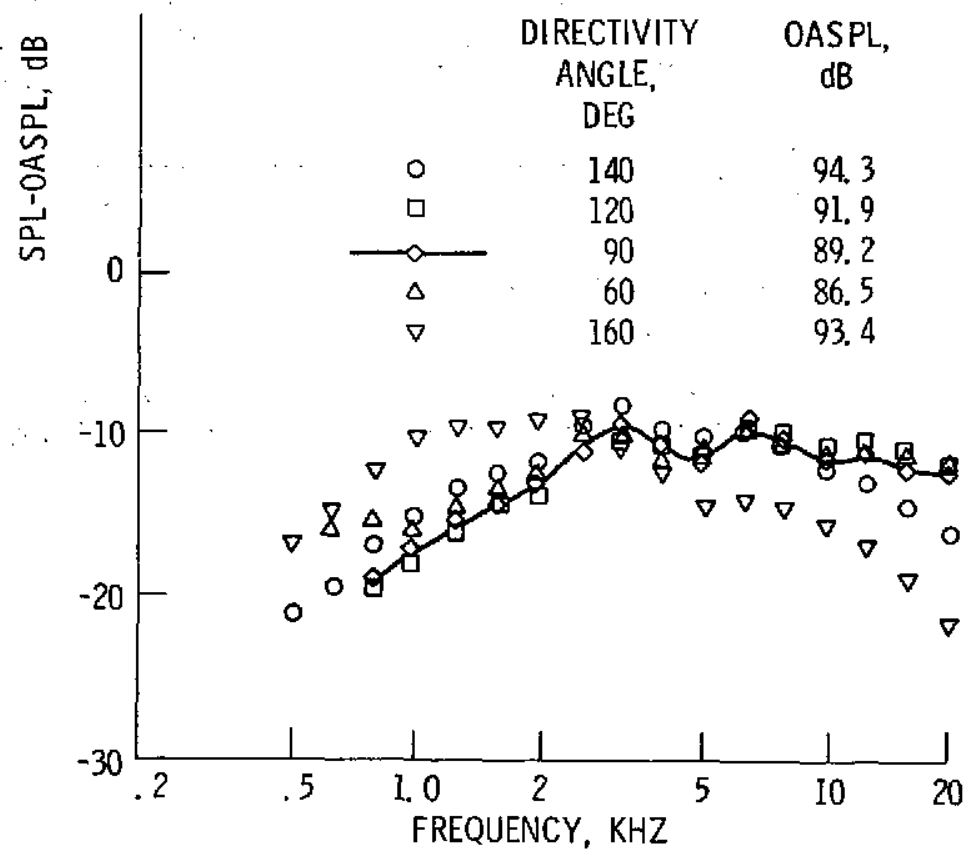

(b) FORWARD VELOCITY, $175 \mathrm{FT} / \mathrm{SEC}$.

Figure 33. - Spectral distribution for 6-tube mixer nozzel with wing. Jet velocity, $840 \mathrm{ft} / \mathrm{sec}$. 


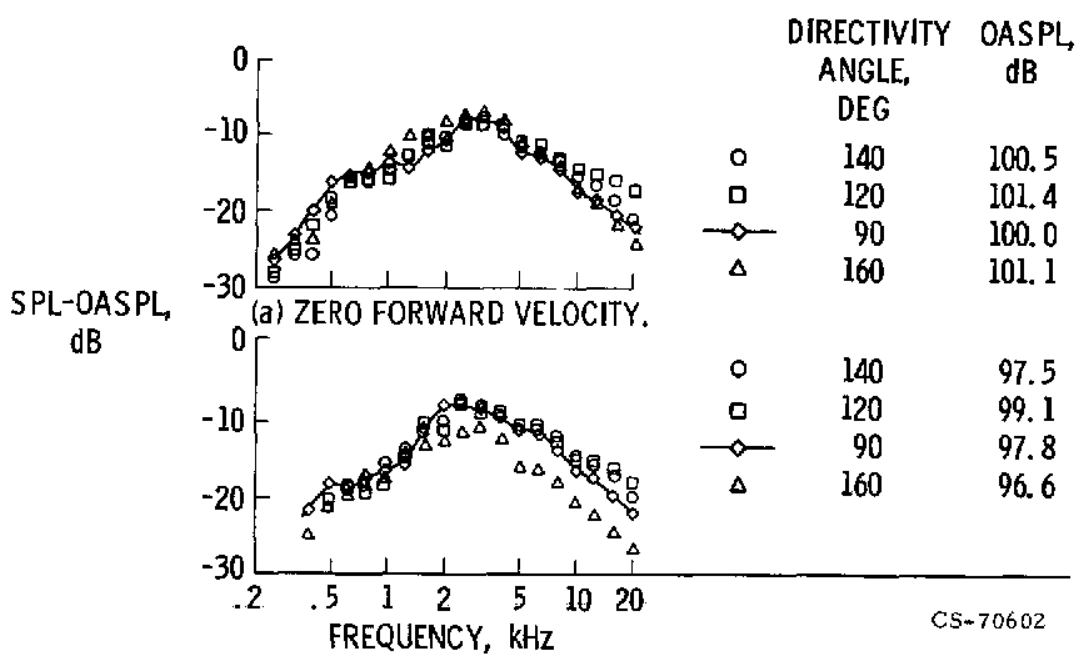

\section{(b) FORWARD VELOCITY, $175 \mathrm{FT} / \mathrm{SEC}$.}

Figure 34. - Spectral distribution for mixer nozzle with ejector and wing. Forward ejector position; jet velocity, $840 \mathrm{ft} / \mathrm{sec}$. 


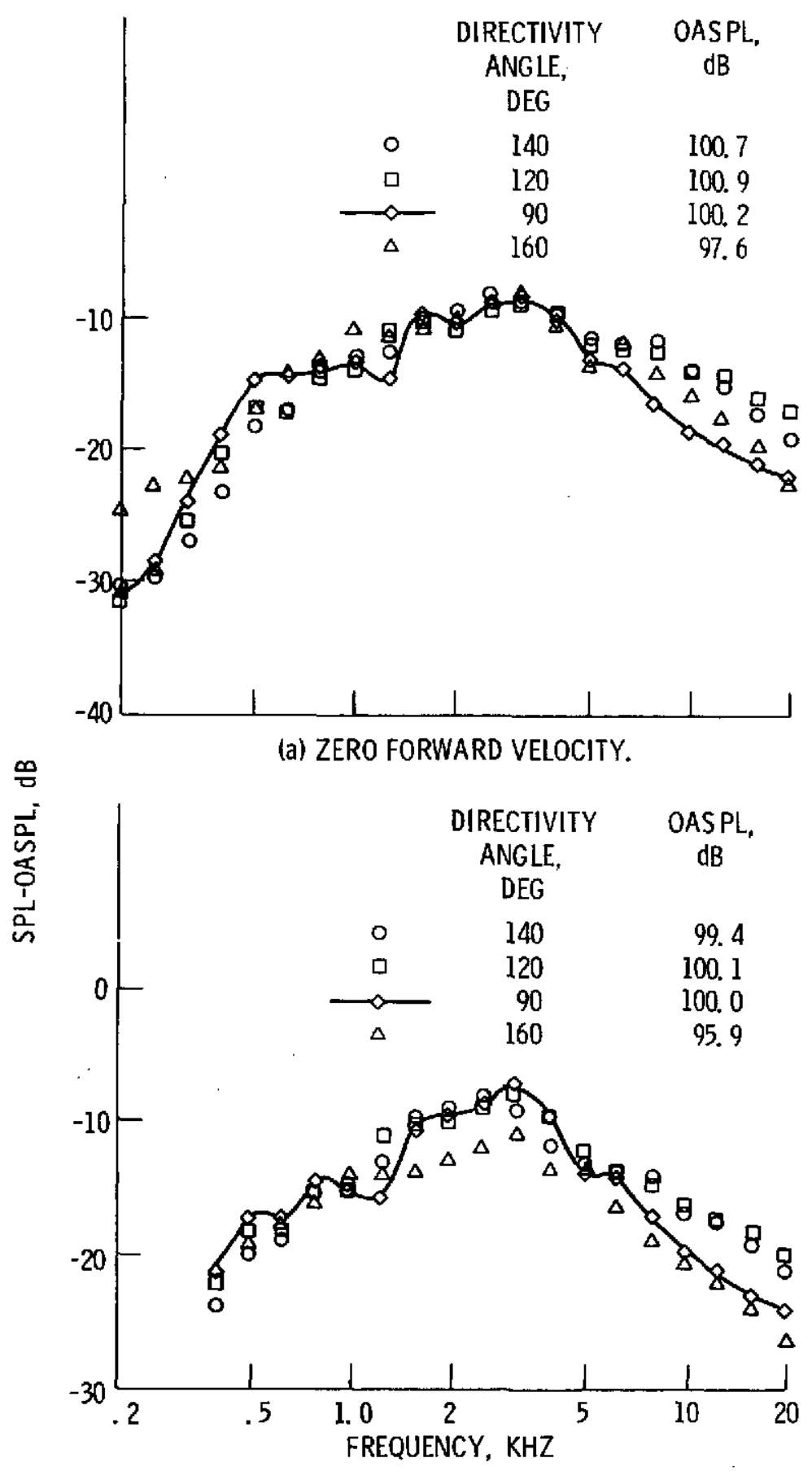

(b) FORWARD VELOCITY, $175 \mathrm{FT} / \mathrm{SEC}$.

Figure 35. - Spectral distribution for mixer nozzle with ejector and wing. Rearward ejector position; jet velocity, $840 \mathrm{ft} / \mathrm{sec}$. 